\title{
Insulin Exacerbates Inflammation in Fibroblast-Like Synoviocytes
}

\author{
Li Qiao, ${ }^{1}$ Yi Li, ${ }^{1}$ and Shui Sun $\mathbb{D}^{1,2}$
}

\begin{abstract}
Osteoarthritis (OA) is considered the most frequent degenerative disease and is characterized by cartilage degradation and synovial inflammation. Fibroblast-like synoviocytes (FLSs) are vital to synovial inflammation in OA. Type 2 diabetes mellitus (T2DM) is characterized by insulin resistance and hyperinsulinemia (HINS) and has been demonstrated to be an independent risk factor for OA. Autophagy is involved in the processes of various inflammatory diseases, and autophagy inhibition can stimulate OA development. Thus, we aimed to investigate the role of insulin in the inflammatory phenotype and autophagy of FLSs in OA. The data showed that cell viability and proinflammatory cytokine production in FLSs were both increased after insulin stimulation. We also found that high insulin could promote macrophage infiltration and chemokine production but inhibited autophagy in FLSs. To further explore the potential mechanisms, the effects of insulin on PI3K/Akt $/ \mathrm{mTOR}$ and NF-KB signaling activation were evaluated. The results indicated that insulin activated $\mathrm{PI} 3 \mathrm{~K} / \mathrm{Akt} / \mathrm{mTOR} / \mathrm{NF}-\mathrm{KB}$ signaling, and the above-mentioned inflammatory responses, including autophagy inhibition, were notably attenuated by specific signaling inhibitors in the presence of high insulin. Moreover, the data showed that a positive feedback loop existed between proinflammatory cytokines (e.g., IL-1 $\beta$, IL-6, and TNF- $\alpha$ ) and PI3K/mTOR/Akt/ NF-KB signaling in FLSs, and insulin enhanced this feedback loop to accelerate OA progression. Our study suggests that insulin may be a novel therapeutic strategy for OA prevention and treatment in the future.
\end{abstract}

KEY WORDS: osteoarthritis; insulin; fibroblast-like synoviocytes; inflammation; autophagy.

\footnotetext{
${ }^{1}$ Department of Joint Surgery, Shandong Provincial Hospital Affiliated to Shandong University, Jinan, 250021, China

${ }^{2}$ To whom correspondence should be addressed at Department of Joint Surgery, Shandong Provincial Hospital Affiliated to Shandong University, Jinan, 250021, China. E-mail: sunshuisph1965@163.com
}

Abbreviations: $O A$, Osteoarthritis; FLSs, Fibroblast-like synoviocytes; T2DM, Type 2 diabetes mellitus; HINS, Hyperinsulinemia; $N F-\kappa B$, Nuclear factor-kappa B; $I L$, Interleukin; $T N F$, Tumor necrosis factor; $M M P$, Matrix metalloproteinase; $L C 3$, Light chain 3

\section{INTRODUCTION}

Osteoarthritis (OA) is an underlying cause of disability and the most frequently occurring degenerative joint disease [1]. Synovial inflammation, including cytokine secretion and inflammatory cell infiltration (primarily macrophages), is one of the characteristic pathological hallmarks of OA [2-5]. There has been increasing evidence from ongoing research that fibroblast-like synoviocytes (FLSs) are vital to the pathogenesis of OA. The synovial membrane, which is important for maintaining the intraarticular environment, can generate synovial fluid to 
maintain joint activity. The synovial membrane is also one of the major sources of intra-articular inflammation and can sustain and even worsen the prognosis of OA by synthesizing proinflammatory cytokines, such as interleukins (ILs) and tumor necrosis factors (TNFs) [6-8]. IL$1 \beta$, IL-6, and TNF- $\alpha$ have been reported as the major proinflammatory cytokines participating in the pathophysiology of OA. The synergistic effects of these three cytokines can facilitate OA $[2,3,9,10]$. Along with FLSs, macrophages also act as crucial components in synovial tissues that participate in OA pathogenesis. Indeed, the degree of macrophage infiltration is a characteristic of $\mathrm{OA}$ and is positively correlated with disease severity $[4,5]$. Thus, synovial inflammation has attracted substantial attention because of its potential as a therapeutic target and its involvement in OA pathogenesis. It is known that the occurrence and development of OA are closely associated with numerous cell signaling pathways. The classical nuclear factor-kappa B (NF-KB) signaling pathway has been reported to be crucial for inducing the expression of various proinflammatory cytokines (e.g., IL-1 $\beta$, IL-6, and TNF- $\alpha$ ) and is considered a potential target in OA progression. Interestingly, these downstream cytokines (e.g., IL-1 $\beta$, IL-6, and TNF- $\alpha$ ) are also important inducers of NF-KB signaling. As a result, this process could form a positive feedback loop to accelerate OA progression $[2,11,12]$. Moreover, proinflammatory cytokines induced by the NF-кB signaling pathway (e.g., IL-1, IL-6, and TNF- $\alpha$ ) could lead to matrix metalloproteinase (MMP) production, causing articular cartilage breakdown and bone resorption in OA progression. Among the MMP family members, MMP-13 and MMP-9 have been reported to be vital for OA progression $[13,14]$. Thus, the potential role of the NF-KB signaling pathway and the targets of inflammatory responses in FLSs were explored in this study.

Recent studies have suggested that metabolic syndrome is closely associated with OA. Indeed, clinical studies have verified that type 2 diabetes mellitus (T2DM), an independent risk factor for OA, is closely associated with the pathological mechanism of OA [15, 16]. Abnormal insulin secretion is a critical characteristic of the early stages of T2DM, and T2DM manifests primarily as hyperinsulinemia (HINS) and insulin resistance. Increased insulin levels can lead to a wide range of effects on metabolism, including increased OA-related proinflammatory cytokine (such as ILs, TNF- $\alpha$, MMP-13) levels [16-19]. Furthermore, by preventing chondrocyte maturation and inducing cartilage degeneration, insulin can aggravate the pathological variations of OA $[19,20]$.
Autophagy, a critical process for maintaining homeostasis, can significantly inhibit inflammation and inflammatory disease progression (e.g., OA) [21-23]. There has been increasing evidence that autophagy deregulation, especially autophagy inhibition, is closely associated with the pathogenesis of OA [23-25]. In the process of autophagy, microtubule-associated protein 1 light chain 3 I (LC3I) is converted to microtubule-associated protein 1 light chain 3 II (LC3II) in autophagosomes. Thus, the expression level of LC3II, an autophagosome-specific marker protein, reflects the number of autophagosomes and thus the autophagy activity [26, 27]. Although the signaling regulators involved in autophagy are sophisticated, the $\mathrm{PI} 3 \mathrm{~K} / \mathrm{Akt} / \mathrm{mTOR}$ pathway has been well accepted as a basic intracellular signaling pathway, and it can inhibit autophagy when activated in OA progression [28, 29]. Moreover, the PI3K/Akt/mTOR pathway has long been considered as the key signaling pathways in cell growth and survival, and the activating factors of this pathway include insulin [30, 31]. In addition, a previous study successfully showed that insulin can exacerbate cartilage degeneration and facilitate OA progression by inhibiting autophagy through the mTOR pathway [20]. Based on the above-mentioned analysis, this study aimed to analyze the inhibitory effect of the PI3K/AKT/mTOR signaling pathway on autophagy and inflammatory responses in FLSs.

The independent effects of high insulin on the biological behavior of FLSs (e.g., proliferation, autophagy, chemotactic effect on macrophages, and inflammatory activity) have never been studied in the literature. This study aimed to explore whether a potential link may exist between T2DM and OA to gain insight into the pathogenesis of OA and introduce new ideas for the clinical management of this disease.

\section{MATERIALS AND METHODS}

\section{Synovial Tissue Collection}

Synovial tissues were collected from patients with OA during knee joint replacement surgery $(n=39 ; 14$ males and 25 females, aged 52 to 79 years old, mean age 63 years old). All patients satisfied the American College of Rheumatology (ACR) diagnostic criteria for OA. Informed consent was obtained from all individual participants included in the study. All experimental procedures for the use of human samples in this study were approved by the Ethics Committee of Shandong Provincial Hospital Affiliated to Shandong University (NO. 2017-53). 


\section{Cell Culture}

OA synovial tissues were macerated, chopped, and then incubated with type II collagenase $(1 \mathrm{mg} / \mathrm{ml}$, Sigma) in Dulbecco's modified Eagle's medium (DMEM, HyClone, Thermo Scientific) for $6 \mathrm{~h}$ at $37{ }^{\circ} \mathrm{C}$ and $5 \%$ $\mathrm{CO}_{2}$ (Thermo Scientific). The tissues were treated with $0.25 \%$ trypsin (Solabio) diluted in a phosphate-buffered saline (PBS) solution at a volume equivalent to that of DMEM. The cells were filtered; incubated overnight in DMEM supplemented with $10 \%$ fetal bovine serum (FBS, HyClone, Thermo Scientific), penicillin (100 IU/ $\mathrm{ml})$, and streptomycin $(100 \mu \mathrm{g} / \mathrm{ml}$, Gibco); and passaged three times. FLSs at passages 4-6 were used for our study.

\section{Stimulation Assays}

FLSs were plated on 6 -well plates $\left(3-5 \times 10^{5}\right.$ cells/ well) or 24 -well plates $\left(8 \times 10^{4}\right.$ cells/well) in high glucose DMEM containing $10 \%$ or $2 \%$ FBS. Insulin $(0,100,200$, or $500 \mathrm{nM}$; Sigma-Aldrich, St. Louis, MO, USA; I0516) or inflammatory stimulators, including IL- $1 \beta$, IL-6, and TNF- $\alpha(0,0.01,0.1,1,10$, or $50 \mathrm{ng} / \mathrm{ml})$, were added and then incubated for the indicated times. PBS was used as a control. PDTC (an NF-KB inhibitor; MCE, USA), LY294002 (a PI3K/Akt inhibitor; MCE, USA), and rapamycin (an mTOR inhibitor; MCE, USA) were used to block the signaling pathways, and an equal amount of inhibitor solvent (0.1\% DMSO, $99.9 \%$ corn oil) was used as a control.

\section{Cell Counting Kit-8}

Cell suspensions were seeded on a 96-well plate at 1000 cells/well. Next, the cells were shaken, incubated for 4 to $6 \mathrm{~h}$ in a $37{ }^{\circ} \mathrm{C}$ incubator until they adhered, and incubated with insulin $(0,100,200$, or $500 \mathrm{nM})$ and with or without each of the inhibitors (LY294002 or rapamycin $[10 \mu \mathrm{M}])$. The control group received the same amount of solvent. After $24 \mathrm{~h}$ or $48 \mathrm{~h}, 100 \mu \mathrm{l}$ of CCK-8 reagent was added to each well, shaken, and subsequently incubated for $2 \mathrm{~h}$. Afterward, the absorbance at $450 \mathrm{~nm}$ was measured with a microplate reader.

\section{Transwell}

According to the source of the supernatant in the lower chamber, the experiments were divided into four groups: the control $(\mathrm{N})$ group, the insulin (ISN)-mediated group (INS group), the fibroblast-like synoviocyte (FLS)mediated group (FLS group), and the INS- and FLS-mediated group (INS+FLS group). When the FLSs in the 24- well plate reached $80 \%$ confluence, the DMEM was replaced with fresh DMEM or with DMEM containing a high INS concentration $(500 \mathrm{nM})$. After $24 \mathrm{~h}, 1000 \mu \mathrm{l}$ of the supernatant from each FLS-plated well under different stimulation conditions (DMEM with or without $500 \mathrm{nM}$ INS) was aspirated and mixed well, and then $600 \mu \mathrm{l}$ of it was added to a lower Transwell chamber (FLS and INS+FLS groups). The supernatant for the control group was $600 \mu \mathrm{l}$ of DMEM, and the supernatant for the INS group was $600 \mu \mathrm{l}$ of DMEM with $500 \mathrm{nM}$ INS; these supernatants were placed in other lower Transwell chambers (N and INS groups) to start the experiments. When FLSs in a 24-well plate reached $80 \%$ confluence, insulin $(500 \mathrm{nM})$ was added for $24 \mathrm{~h}$. Then, $600 \mu \mathrm{l}$ of the supernatant was aspirated and added to the lower Transwell chamber. After macrophage digestion, a cell suspension was prepared with DMEM/F12 medium, and $200 \mu \mathrm{l}$ was added to the upper Transwell chamber. Next, the cells were incubated overnight, and the cells that did not migrate were wiped away with a cotton swab. Then, the cells in the lower chamber were stained with hematoxylin for $10 \mathrm{~min}$ at ambient temperature. The number of migrated cells was examined using a cell counter with microscopic imaging system.

\section{Reverse Transcription-Quantitative Polymerase Chain Reaction}

FLSs were plated in 24-well plates and cultured in the presence of insulin $(0,100,200$, or $500 \mathrm{nM})$, the inflammatory stimulators IL- $1 \beta$, IL- 6 , and TNF- $\alpha(0,0.01,0.1$, 1,10 , or $50 \mathrm{ng} / \mathrm{ml}$ ), or different signaling inhibitors (PDTC, LY294002, or rapamycin); then, the cells were analyzed 6, 12 , or $24 \mathrm{~h}$ after treatment. Total RNA was extracted from FLSs using TRIzol reagent (Invitrogen) and reversetranscribed using a ReverTra Ace qPCR RT kit (Toyobo, Japan) following the manufacturer's protocol. Reverse transcription-quantitative polymerase chain reaction (RTqPCR) was performed using a LightCycler 480 (Roche, Basel, Switzerland) according to the following protocol: denaturation at $95^{\circ} \mathrm{C}$ for $10 \mathrm{~min}, 40$ cycles of denaturation at $95{ }^{\circ} \mathrm{C}$ for $10 \mathrm{~s}$, annealing at $60{ }^{\circ} \mathrm{C}$ for $1 \mathrm{~min}$, and extension at $72{ }^{\circ} \mathrm{C}$ for $1 \mathrm{~s}$. The primers for RT-qPCR were designed according to the consensus sequences by Oligo. GAPDH was used as an internal loading control. The forward and reverse primers are listed in Table 1, and all primers were created by BGI (Beijing, China). To measure the relative messenger RNA (mRNA) levels, the 2- $\Delta \Delta$ cycle threshold (2- $\Delta \Delta \mathrm{CT})$ method was used. 
Table 1. Primers used for real-time polymerase chain reaction

\begin{tabular}{ll}
\hline Primer name & Primer base sequence (5' to 3') \\
\hline GAPDH & Forward:CACCATCTTCCAGGAGC \\
IL-1 $\beta$ & Reverse:AGTGGACTCCACGACGTA \\
IL-6 & Forward:CTAAAGTATGGGCTGGACTG \\
& Reverse:AGCTTCAATGAAAGACCTCA \\
TNF $\alpha$ & Forward:ACTCACCTCTTCAGAACGAATTG \\
& Reverse:CCATCTTTGGAAGGTTCAGGTTG \\
MMP-9 & Forward:TGTCTACTGAACTTCGGGGT \\
& Reverse:TCACAGAGCAATGACTCCAA \\
MMP-13 & Forward:TTGACAGCGACAAGAAGTGG \\
& Reverse:GCCATTCACGTCGTCCTTAT \\
IL1R1 & Forward:CGCGTCATGCCAGCAAATTCCATT \\
& Reverse:TCCATGTGTCCCATTTGTGGTGTG \\
IL1R3 & Forward:TTCCTGCTAAGGTGGAGGATTC \\
& Reverse:GCTCATTCTCCACAAATTTGC \\
IL6R & Forward:CTCAGAACGCTGCGATGACT \\
GP130 & Reverse:CGGTCCTGCCTAGTCCAATAC \\
& Forward:TCTGGAAACTATTCATGCTACCG \\
TNFR1 & Reverse:ACTCACAAACAACATTGCTGAGG \\
& Forward:TCTGGAAACTATTCATGCTACCG \\
TNFR2 & Reverse:ACTCACAAACAACATTGCTGAGG \\
& Forward:AGGAGAAACAGAACACCGTGTG \\
\hline
\end{tabular}

$I L$ interleukin, $T N F$ tumor necrosis factor, $M M P$ matrix metalloproteinase, ILIR interleukin-1 receptor, IL6R interleukin-6 receptor, GP glycoprotein, $T N F R$ tumor necrosis factor receptor

\section{Enzyme-Linked Immunosorbent Assay}

Cells were cultured and then stimulated as described above, and the supernatants were collected at $6 \mathrm{~h}, 12 \mathrm{~h}$, or $24 \mathrm{~h}$. The release of proinflammatory cytokines (IL-1 $\beta$, IL6 , and TNF- $\alpha$ ), matrix metalloproteinases (MMP-9 and MMP-13), and chemokines (CXCL12, CCL2/MCP-1, and CCL5/RANTES) was analyzed using enzyme-linked immunosorbent assay (ELISA) kits (Multi Sciences, Hang Zhou, China) following the manufacturer's instructions.

\section{Western Blotting}

Whole cell lysates were separated by SDSpolyacrylamide gel electrophoresis (SDS-PAGE) and then transferred onto a polyvinylidene difluoride membrane (Merck Millipore, Darmstadt, Germany). Western blotting was performed using anti-LC3I (1:1000, Abcam, USA), anti-LC3II (1:1000, Abcam, USA), anti-PI3K (1:1000, CST), anti-phospho-PI3K (1:500, CST), anti-Akt $(1: 3000$, CST), anti-phospho-Akt $(1: 1000$, CST), antimTOR (1:3000, CST), anti-phospho-mTOR (1:1000, CST), anti-phospho-p50 NF-kB (1:1000, CST), p50 NF-
кB (1:2000, CST), anti-phospho-p65 NF-кB (1:1000, CST), and anti-p65 NF-kB (1:2000, CST) antibodies. GAPDH (1:10000, Abcam, USA) was used as a loading control for proteins. The band intensities were analyzed using an ECL Plus detection system (Thermo Scientific, Pittsburgh, PA, USA).

\section{Immunofluorescence}

FLSs were grown in 6-well plates with high insulin stimulation (500 nM) for $24 \mathrm{~h}$. Preconditioned cells were washed slowly three times with PBS for 5 min each, fixed with $4 \%$ paraformaldehyde for $30 \mathrm{~min}$, washed three times with PBS (5 min each), and then treated with $5 \%$ bovine serum albumin (BSA) for $1 \mathrm{~h}$. The cells were then incubated with anti-p50 (1:100 dilution) and anti-p65 (1:150 dilution) antibodies at $4{ }^{\circ} \mathrm{C}$ overnight. After the cells were washed slowly three times with PBS for 5 min each, FITCand TRITC-conjugated secondary antibodies were used to visualize the proteins under a fluorescence microscope (Olympus, Tokyo, Japan). Nuclei were counterstained with 4',6'-diamidino-2-phenylindole (DAPI). 

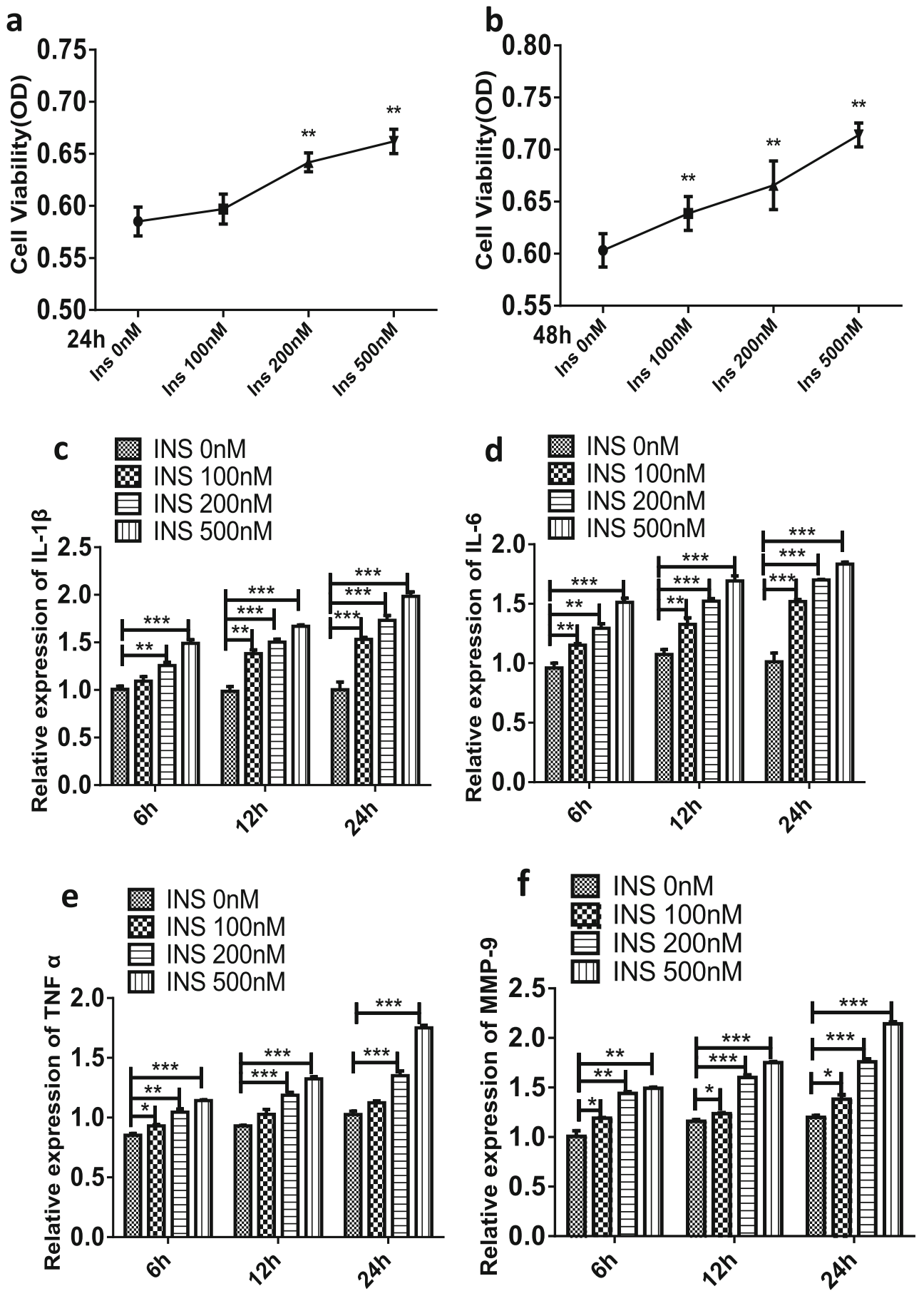

Fig. 1. Cell viability and proinflammatory cytokines were both increased in response to high insulin in FLSs. a, b CCK-8 technology was used to assess cell viability of FLSs following insulin treatment $(0,100,200,500 \mathrm{nM})$ for 24 or $48 \mathrm{~h}$; a representative of three independent experiments is shown. The figure of optical density (OD) detected by CCK-8 was used to reflect the degree of cell viability. FLSs were treated with insulin $(0,100,200,500 \mathrm{nM})$ for 6,12 , or $24 \mathrm{~h}$. c-g The relative expression of IL-1 $\beta$, IL-6, TNF- $\alpha$, MMP-9, and MMP-13 were measured by RT-qPCR. h-1 The secretion of IL-1 $\beta$, IL-6, TNF- $\alpha$, MMP-9, and MMP-13 were measured by ELISA. All the results are expressed as the mean \pm SEM of three experiments conducted in triplicate separately. $* P<0.05$, $* * P<0.01$, and $* * * P<0.001$ vs. control group. 

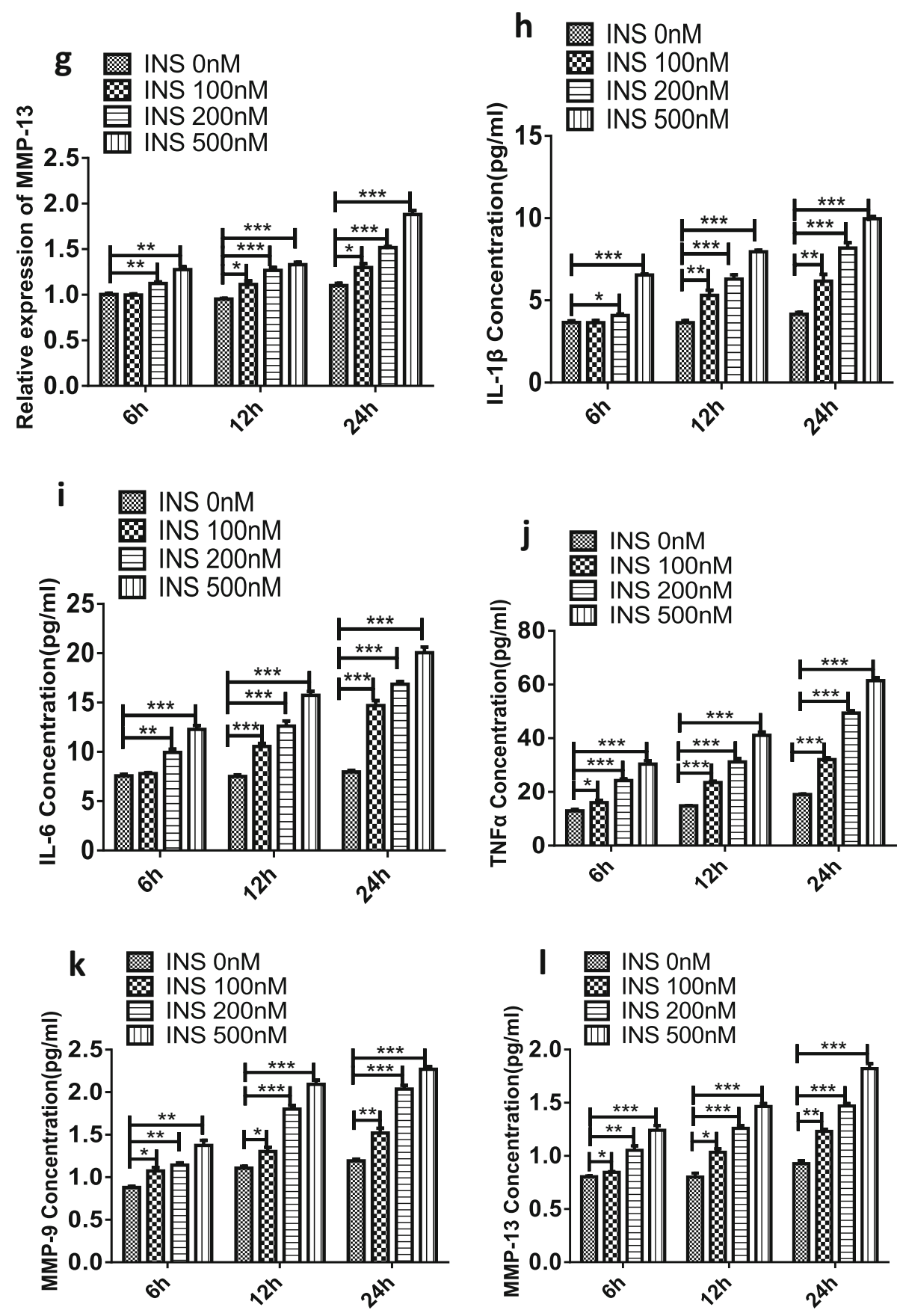

Fig. 1. (continued)

\section{Statistical Analysis}

Statistical analysis was conducted using the GraphPad Prism 5 software package (La Jolla, CA, USA). A $t$ test was used to assess significant differences between

two groups. The results of three different experiments are expressed as the mean \pm SEM. Differences in the results with $P<0.05$ were considered statistically significant. 


\section{RESULTS}

\section{FLSs Are Sensitive to Insulin}

A previous study suggested that FLSs are vital for osteoarthritis pathogenesis and that synoviocyte hyperplasia and abnormal synoviocyte proinflammatory cytokine production were both important pathological hallmarks of OA [2-5]. CCK-8 assays were applied to assess the effects of insulin $(0,100,200$, or $500 \mathrm{nM})$ on the viability of FLS. In response to insulin ( 200 or $500 \mathrm{nM})$, cell viability was significantly enhanced at $24 \mathrm{~h}$ (Fig. 1a) and $48 \mathrm{~h}$ (Fig. 1b). Next, the regulatory effects of insulin on proinflammatory cytokines and MMP mechanisms in FLSs were investigated. To determine whether insulin can directly regulate proinflammatory cytokine expression, FLSs were treated with incremental concentrations of insulin $(0,100,200$, or $500 \mathrm{nM}$ ). The qRT-PCR results (Fig. 1c-g) showed that IL$1 \beta$, IL-6, TNF- $\alpha$, MMP-9, and MMP-13 expression levels were increased in a concentration-dependent manner compared with those of the control group $(P<0.05)$ at $6 \mathrm{~h}$, $12 \mathrm{~h}$, and $24 \mathrm{~h}$ after treatment with insulin $(0,100,200$, or $500 \mathrm{nM}$ ), and these levels were increased most significantly at $24 \mathrm{~h}$. A similar increase in FLS secretion in response to insulin stimulation was observed by ELISA (Fig. 1h-1).

\section{Insulin Enhanced FLS-Mediated Chemotaxis in Macrophages}

Because macrophage infiltration is a significant pathological feature of OA, macrophages can also contribute to OA $[4,5]$. Chemokines are the major drivers of leukocyte adhesion and cell migration in inflammatory disease development $[32,33]$. Among the chemokines, CXCL12, CCL2/MCP-1, and CCL5/RANTES can induce macrophage chemotaxis and are closely involved in OA development [34-36]. It is unclear whether insulin can regulate FLS-mediated macrophage infiltration and chemokine production. Transwell assays were employed to analyze the role of insulin in macrophage infiltration. The results suggest that the number of transmigrated macrophages was significantly increased at $24 \mathrm{~h}$ in the presence of FLSs treated with high insulin $(500 \mathrm{nM})$. In addition, ELISA was used to detect CXCL12, CCL2/MCP-1, and CCL5/ RANTES secretion by FLSs after $24 \mathrm{~h}$. It was observed that insulin could independently attract macrophages in the absence of FLSs (Fig. 2a). Moreover, CXCL12, CCL2/MCP-1, and CCL5/RANTES secretion increased following insulin stimulation (500 nM, Fig. 2b-d).

\section{Insulin Activates the PI3K/mTOR/Akt and NF-KB Pathways and Mediates Autophagy Inhibition}

The above-mentioned data suggest that insulin could increase the inflammatory effect of FLSs. The PI3K/Akt/ mTOR signaling pathway is involved in the pathogenesis of inflammation, including OA [28-31], and NF-KB is a known signaling pathway of OA inflammation [11, 12]. Thus, whether insulin can regulate PI3K/Akt/mTOR and NF-KB signaling pathway activation in FLSs was verified. Western blotting was used to evaluate the phosphorylation of PI3K/Akt/mTOR and p50/p65 (NF-KB subunits). According to the Western blotting results, the phosphorylation of PI3K/Akt/mTOR (Fig. 3a) and p50/p65 (Fig. 3b) was increased remarkably in FLSs treated with high insulin concentrations $(100,200$, or $500 \mathrm{nM})$ for $24 \mathrm{~h}$. These results verified PI3K/Akt/mTOR and NF-кB signaling pathway activation by high insulin conditions in FLSs. Immunofluorescence confirmed that a high insulin level $(500 \mathrm{nM})$ could improve p50 and p65 (Fig. 3c, d) translocation into the nucleus in FLSs.

Autophagy is a critical cellular process that maintains homeostasis, and autophagy inhibition is closely associated with OA [21-25]. To evaluate how insulin regulates autophagy activation in FLSs, Western blotting was employed to detect the expression of LC3II, a major autophagy effector. LC3II expression and the LC3II/LC3I ratio were decreased with concomitantly increased $\mathrm{PI} 3 \mathrm{~K} / \mathrm{Akt} / \mathrm{mTOR}$ phosphorylation levels (Fig. 3a).

\section{Insulin Exacerbates Inflammatory Responses and Inhibits Autophagy in a Manner Dependent on the PI3K/mTOR/Akt and NF-KB Pathways}

According to the above-mentioned data, insulin could activate the PI3K/Akt/mTOR and NF-KB signaling pathways in FLSs (Fig. 3a-c). In addition, the PI3K/Akt/ mTOR pathway is a fundamental intracellular signaling pathway that is widely involved in autophagy regulation $[28,29]$. To further verify the regulation of both signaling pathways by insulin, the effects of specific inhibitors on insulin-induced inflammatory response exacerbation and autophagy inhibition were also studied. The data revealed that inhibiting the PI3K/Akt/mTOR signaling pathways could eliminate the increased FLS viability following insulin treatment $(0,100,200$, or $500 \mathrm{nM})$ for 24 or $48 \mathrm{~h}$ (Fig. 4a, b). Furthermore, the decreases in LC3II expression and the LC3I/LC3I ratio caused by insulin $(500 \mathrm{nM})$ could be restored by inhibitor treatment. The results demonstrated that the PI $3 \mathrm{~K} / \mathrm{Akt} / \mathrm{mTOR}$ pathway plays a role in autophagy regulation in FLSs (Fig. 4c). 

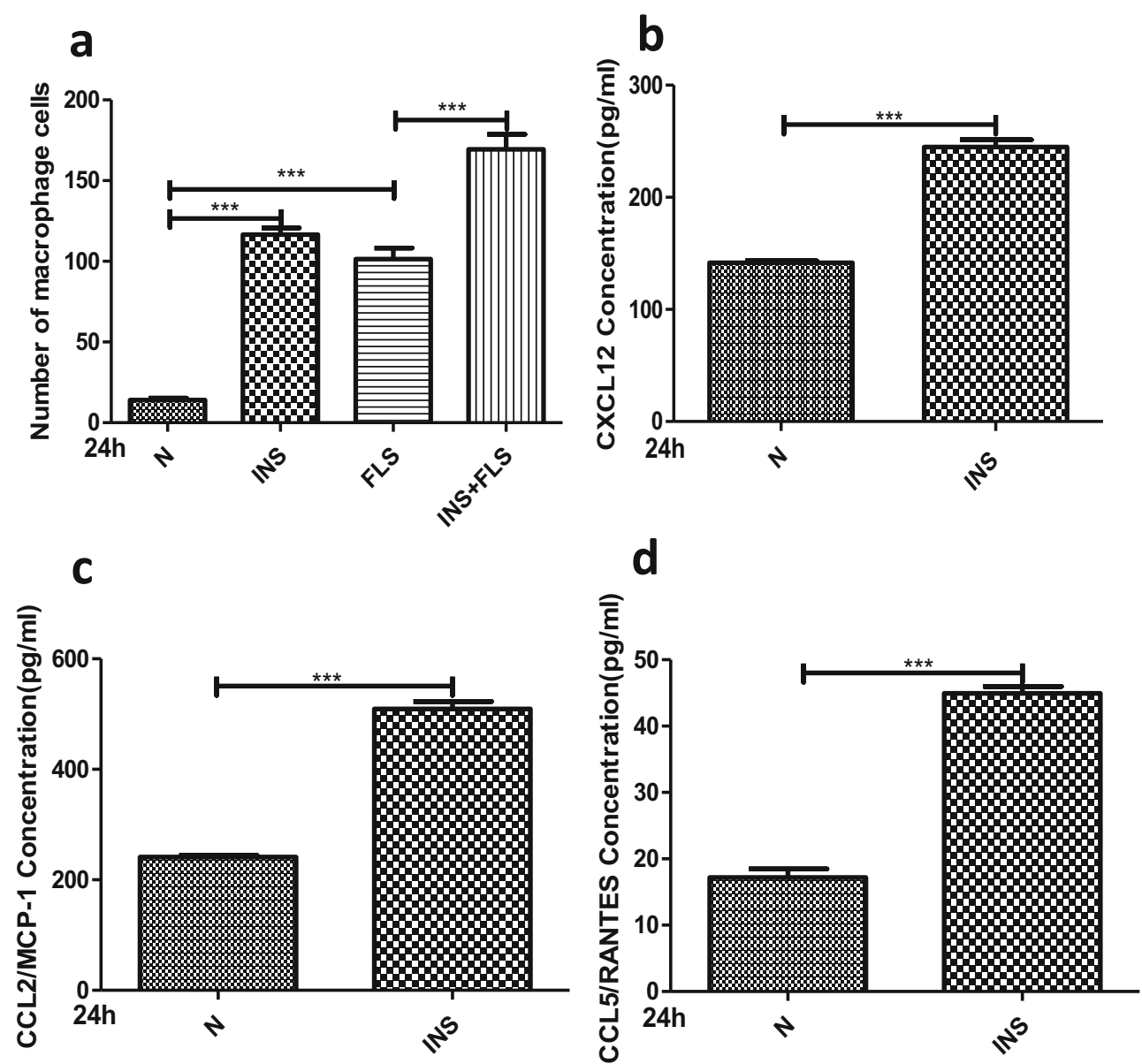

Fig. 2. Effect of insulin on chemotaxis of FLSs to macrophages. FLSs received the treatment of high insulin ( $500 \mathrm{nM})$ for $24 \mathrm{~h}$. a The chemotactic ability of FLSs was performed by Transwell assay and the average number of macrophage cells that invaded through the filter was quantified. Migration capacity of macrophage was measured by Transwell assay. b-d ELISA were performed to detect the secretion of CXCL12, CCL2/MCP-1, and CCL5/RANTES by high insulin $(500 \mathrm{nM})$ after $24 \mathrm{~h}$. All the results are expressed as the mean \pm SEM of three experiments performed in triplicate separately. $* * * P<0.001 v s$. control group.

Because NF-KB signaling could significcytokines (e.g., IL-1 $\beta$, IL-6, and TNF- $\alpha$ ) directly and MMPs indirectly [11-14], we speculated that the overproduction of proinflammatory factors and chemokines following insulin treatment might result from NF-KB signaling pathway activation. To verify the mechanism of high insulininduced proinflammatory factor and chemokine production, an inhibitor targeting the NF-кB (PDTC, $10 \mu \mathrm{M}$ ) signaling pathway was used. To evaluate the role of different pathways involved in OA progression, inhibitors targeting the PI3K/Akt/mTOR signaling pathway (LY294002, rapamycin) were employed. Subsequently, the inhibition of NF-KB signaling pathway could inhibit the CXCL12, CCL2/MCP-1, and CCL5/RANTES oversecretion induced by a high insulin concentration $(500 \mathrm{nM})$ at
$24 \mathrm{~h}$ (Fig. 4d-f). Similar results showing that inhibiting the $\mathrm{PI} 3 \mathrm{~K} / \mathrm{AKT} / \mathrm{mTOR}$ and NF-KB signaling pathways could reduce the overexpression (Fig. $4 \mathrm{~g}-\mathrm{k}$ ) and secretion (Fig. $41-p)$ of IL- $1 \beta$, IL-6, TNF- $\alpha$, MMP-9, and MMP-13 induced by a high insulin concentration $(500 \mathrm{nM})$ at $24 \mathrm{~h}$ were also obtained. These experiments provide evidence that the proinflammatory effect of insulin on FLSs could be exerted through $\mathrm{PI} 3 \mathrm{~K} / \mathrm{mTOR} / \mathrm{Akt}$ and NF-KB pathway activation.

\section{Insulin Sensitizes FLSs to Inflammatory Factors by Upregulating Their Surface Receptors}

NF-KB contributes to the production of proinflammatory cytokines (e.g., IL-1 $\beta$, IL-6, and TNF- $\alpha$ ), and in turn, 
a

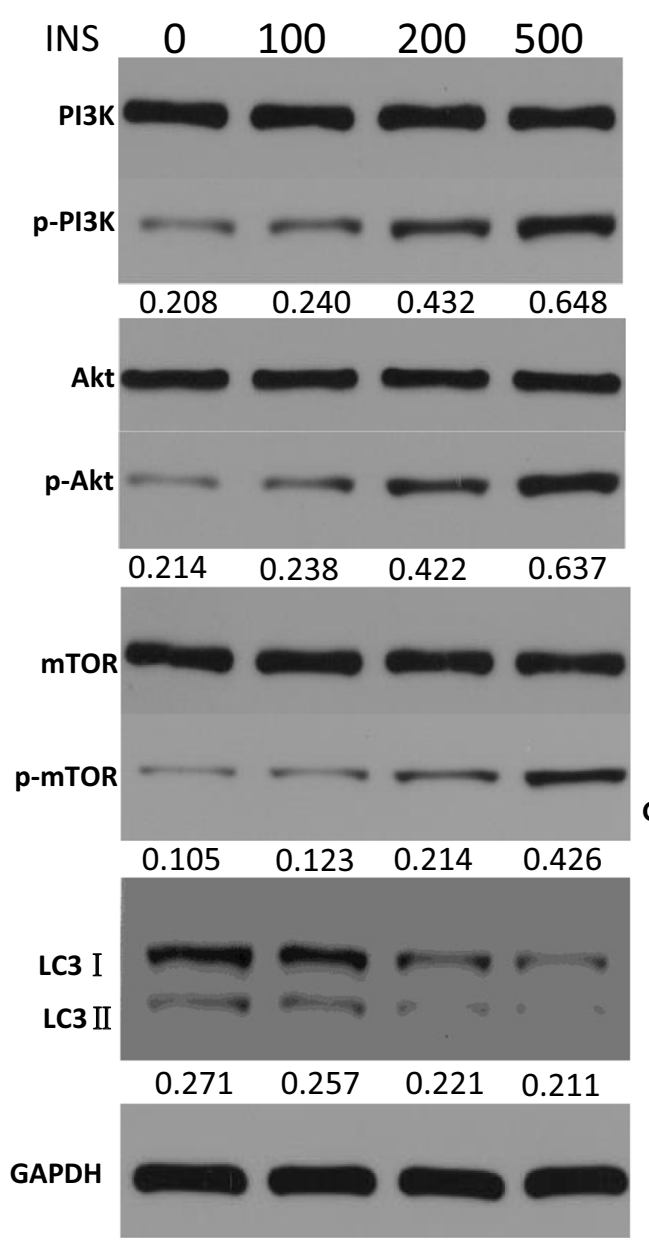

b

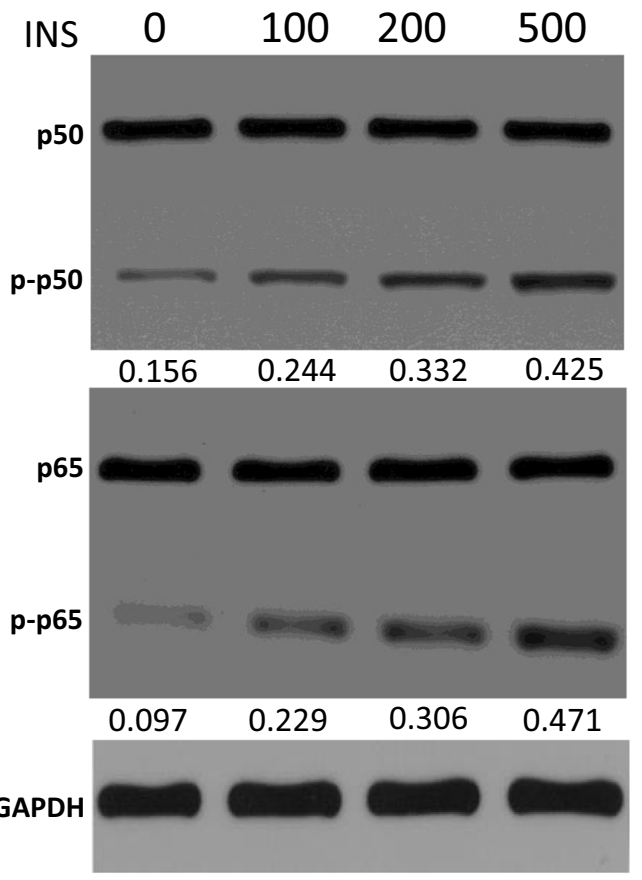

Fig. 3. Activation of PI3K/Akt/Mtor/NF-kB pathway and autophagy deficiency by insulin. a, b Western blot analysis was used to examine the phosphorylation level of PI3K/Akt/mTOR and p50/p65 in FLSs treated with insulin (INS: 0, 100, 200, $500 \mathrm{nM}$ ) for $24 \mathrm{~h}$. c, d Effects of insulin (INS: $500 \mathrm{nM}$ ) on p50 and p65 nuclear translocation in FLSs were observed using confocal fluorescence microscopy. a Western blot analysis was used to examine ratio of LC3 I/II in FLSs treated with insulin (Ins; 0, 100, 200, $500 \mathrm{nM}$ ) for $24 \mathrm{~h}$. Results are expressed as the mean \pm SEM of three experiments conducted in triplicate separately. All the results are expressed as the mean \pm SEM of three experiments conducted in triplicate separately.

the proinflammatory effects of IL- $1 \beta$, IL- 6 , and TNF- $\alpha$ are mediated through the activation of several signaling pathways, including NF-KB signaling $[2,11,12]$. Thus, a feedback mechanism exists among inflammatory cytokines and signaling pathways, which can activate each other and have a close relationship. Based on the fact that insulin is a positive regulator of proinflammatory cytokine production and was found to upregulate the downstream targets of PI3K/mTOR/Akt/NF-KB signaling in FLSs, we hypothesized that insulin might be involved in the interaction between IL- $1 \beta / \mathrm{IL}-6 / \mathrm{TNF}-\alpha$ and PI3K/mTOR/Akt/ NF-KB signaling. Cytokines act as important mediators of intercellular communication through specific cytokine receptors on the cell surface and initiate a series of specific biochemical reactions. The receptors responsible for the proinflammatory effects of IL-1 $\beta / \mathrm{IL}-6 / \mathrm{TNF}-\alpha$-activated intracellular signaling pathways include interleukin-1 receptor 1 (IL-1R1), interleukin-1 receptor 3 (IL-1R3, interleukin-1 receptor accessory chain), interleukin-6 receptor (IL-6R), glycoprotein 130 (GP130, interleukin-6 coreceptor), tumor necrosis factor receptor 1 (TNFR1 or p55), and tumor necrosis factor receptor 2 (TNFR2 or p75) [37-39]. Thus, we measured the expression of these proinflammatory cytokine receptors in insulin-stimulated FLSs 

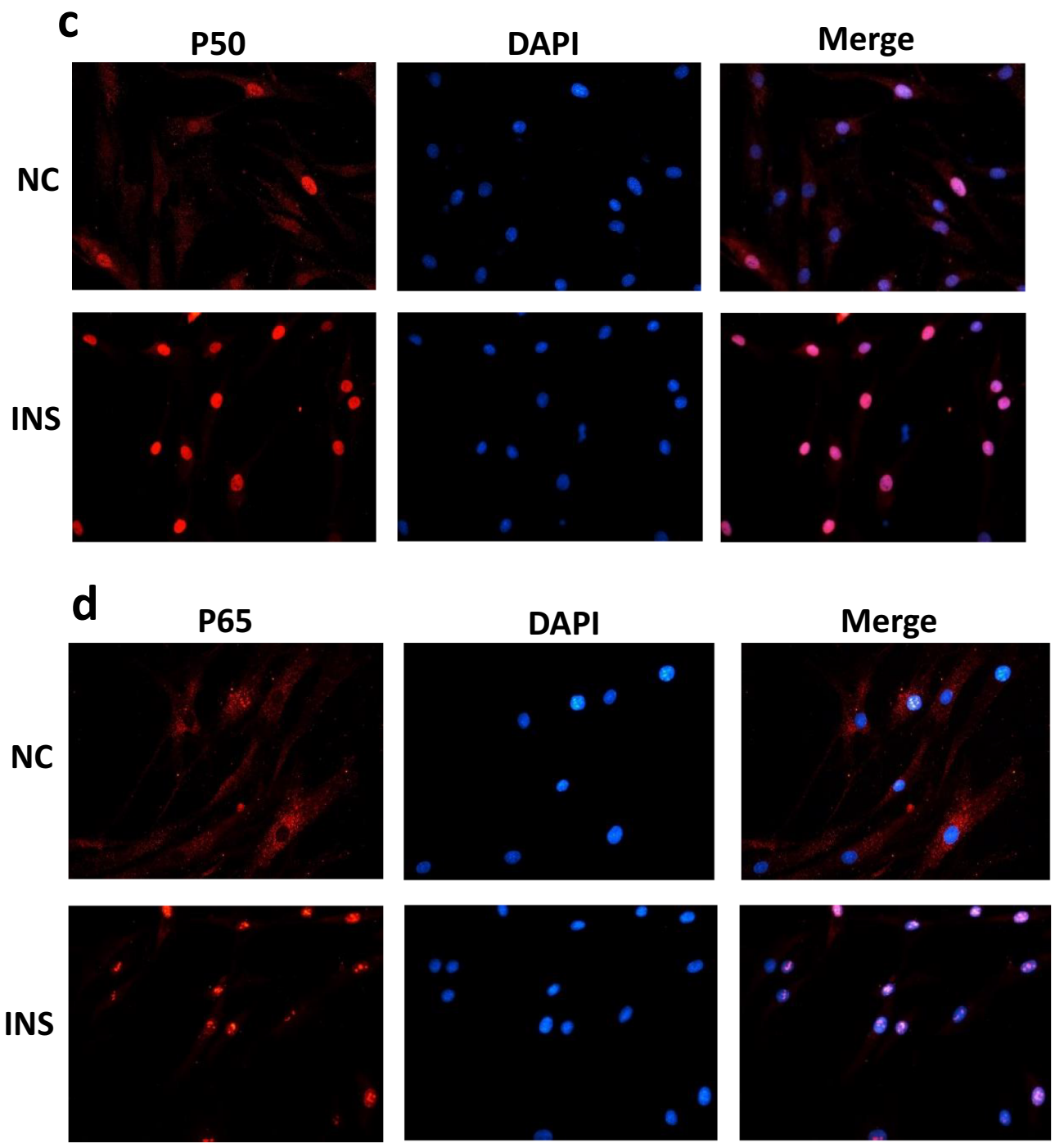

Fig. 3. (continued)

by qRT-PCR. The results showed that IL-1R1, IL-1R3, IL6R, GP130, TNFR1, and TNFR2 expression levels were increased in a concentration-dependent manner compared with those of the control group $(P<0.05)$ at $24 \mathrm{~h}$ after treatment with insulin $(0,100,200$, or $500 \mathrm{nM})$; these receptors were upregulated most significantly at the $500 \mathrm{nM}$ concentration (Fig. 5a-f). To explore the association of cytokine receptor upregulation with $\mathrm{PI} 3 \mathrm{~K} / \mathrm{mTOR} /$ Akt/NF-kB signaling in FLSs, the effect of inhibitors targeting the PI3K/Akt (LY294002, $10 \mu \mathrm{M}$ ), mTOR (rapamycin, $10 \mu \mathrm{M}$ ), and NF-кB (PDTC, $10 \mu \mathrm{M}$ ) signaling pathways on insulin-induced cytokine receptor expression was studied. The data revealed that inhibiting the $\mathrm{PI} 3 \mathrm{~K} / \mathrm{Akt} / \mathrm{mTOR}$ and NF-KB signaling pathways could reduce the IL-1R1, IL-1R3, IL-6R, GP130, TNFR1, and TNFR2 overexpression induced by high insulin $(500 \mathrm{nM})$ at $24 \mathrm{~h}$ (Fig. $5 \mathrm{~g}-1$ ). These experiments provide evidence that when FLSs are stimulated with insulin, the expression of proinflammatory cytokine (e.g., IL1- $\beta$, IL6, and TNF$\alpha)$ receptors depends on $\mathrm{PI} 3 \mathrm{~K} / \mathrm{Akt} / \mathrm{mTOR}$ and $\mathrm{NF}-\mathrm{kB}$ signaling pathway activation.

Insulin and Inflammatory Factors Synergistically Exacerbated the Inflammatory Phenotype of OA FLSs

In synovial joint pathology, a major hallmark in response to increased levels of IL- $1 \beta$, IL- 6 and TNF- $\alpha$ is the overexpression of MMPs, including MMP-9 and MMP- 

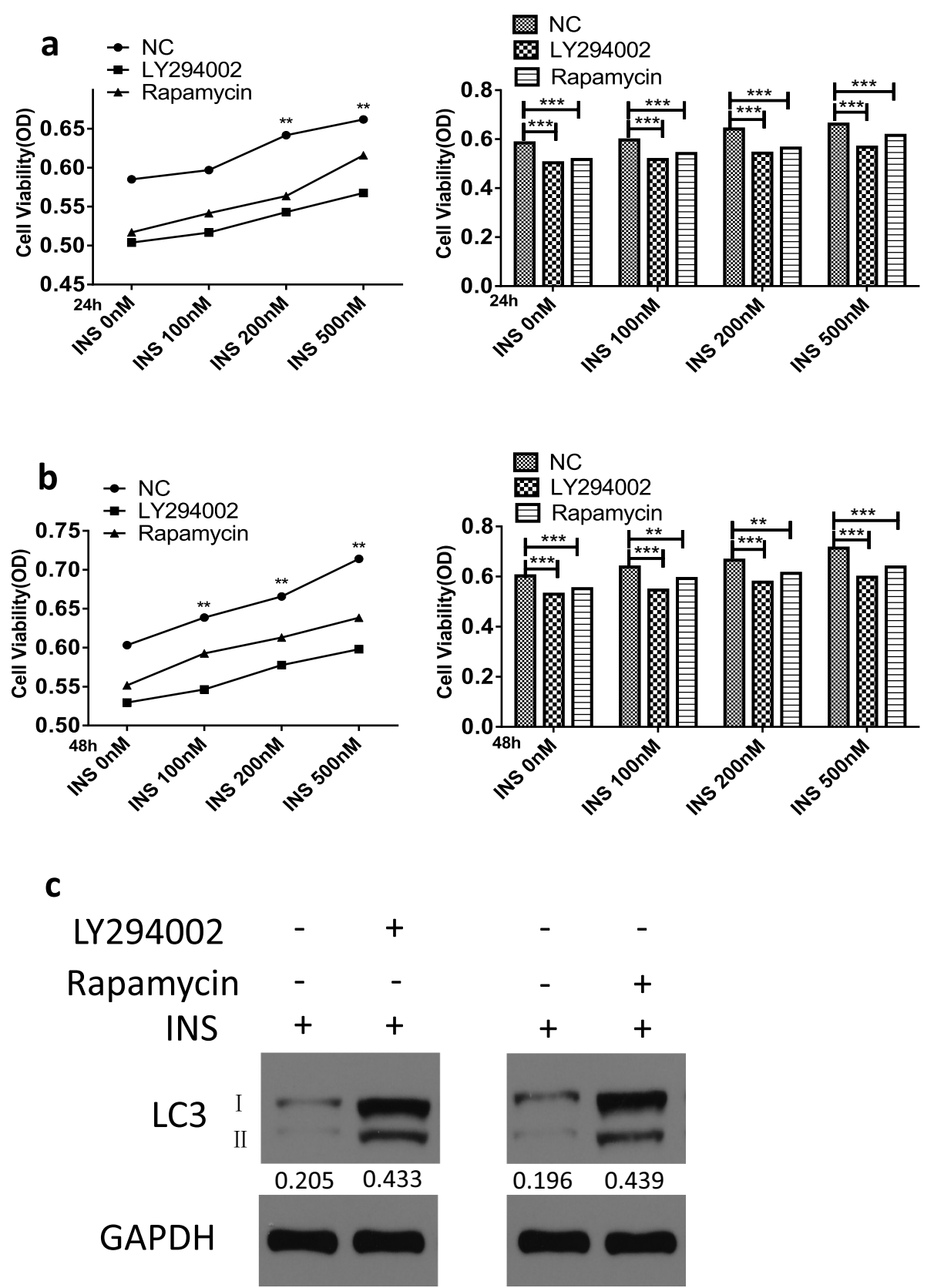

Fig. 4. High insulin-mediated inflammatory responses are dependent on PI3K/Akt/mTOR and NF-kB pathway. a, b FLSs were treated with insulin (INS; 0 , 100, 200, $500 \mathrm{nM}$ ) in the presence of inhibitor targeting PI3K/Akt (LY294002, $10 \mu \mathrm{M}$ ) and mTOR (Rapamycin, $10 \mu \mathrm{M})$ signaling. CCK-8 technology was used to assess cell viability of FLSs treated with a duration of $24 \mathrm{~h}$ or $48 \mathrm{~h}$. $\mathbf{c}$ Various inhibitors targeting PI3K/Akt (LY294002, $10 \mu \mathrm{M})$ and mTOR (Rapamycin, $10 \mu \mathrm{M}$ ) were pre-treated for $6 \mathrm{~h}$ respectively to antagonize the effects of high insulin $(500 \mathrm{nM})$ stimulation with a duration of $24 \mathrm{~h}$. Ratio of LC3 I/II was determined by WB. d-f ELISA were performed to detect the secretion of CXCL12, CCL2/MCP-1, and CCL5/RANTES by high insulin (500 nM) in the presence of NF-KB inhibitor (PDTC, $10 \mu \mathrm{M}$ ) after $24 \mathrm{~h}$. Various inhibitors targeting NF-KB (PDTC, $10 \mu \mathrm{M})$, PI3K/Akt (LY294002, $10 \mu \mathrm{M})$, and mTOR (Rapamycin, $10 \mu \mathrm{M}$ ) were pre-treated for $6 \mathrm{~h}$ to antagonize the effects of insulin stimulation with a duration of $24 \mathrm{~h}$. $\mathbf{g}-\mathbf{k}$ RT-qPCR was performed to ascertain the relative expression of IL-1 $\beta$, IL-6, TNF- $\alpha$, MMP-9, and MMP-13 in FLSs. 1-p ELISA was performed to ascertain the secretion of IL-1 $\beta$, IL-6, TNF- $\alpha$, MMP-9, and MMP-13 in FLSs. Results are expressed as the mean \pm SEM of three experiments conducted in triplicate separately. All the results are expressed as the mean $\pm \mathrm{SEM}$ of three experiments conducted in triplicate separately. ${ }^{*} P<0.05$. ${ }^{*} P<0.01$. ${ }^{*} * * P<0.001$ vs. control group. 

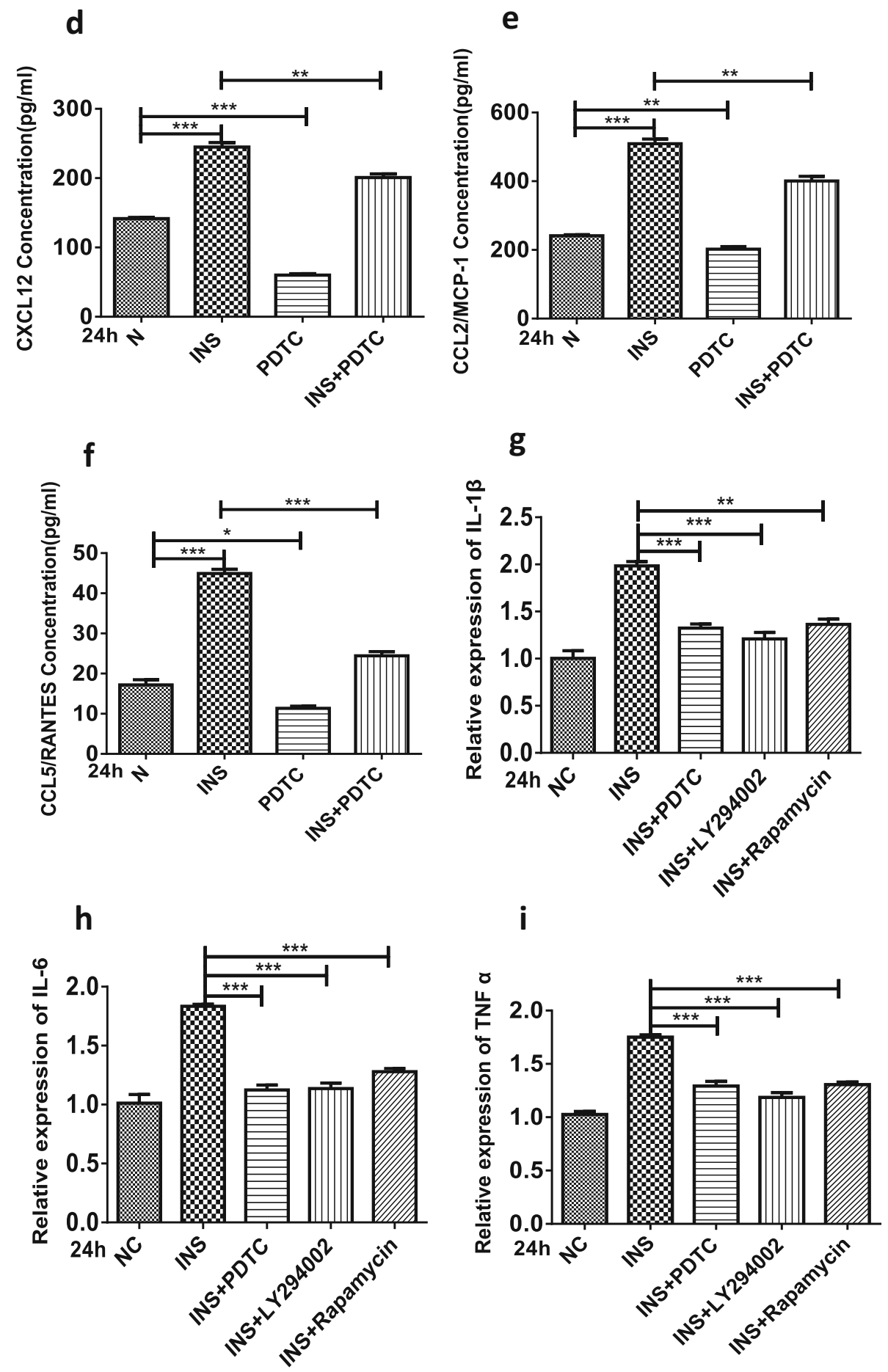

Fig. 4. (continued)

13, which contributes to cartilage degradation $[13,14]$. To determine whether insulin can directly regulate cytokinemediated inflammatory reactions, we chose MMP-9 and
MMP-13 expression as a functional readout for the effect of insulin. FLSs were treated with incremental concentrations of IL- $1 \beta$, IL- 6 and TNF- $\alpha(0,0.01,0.1,1,10$, or 

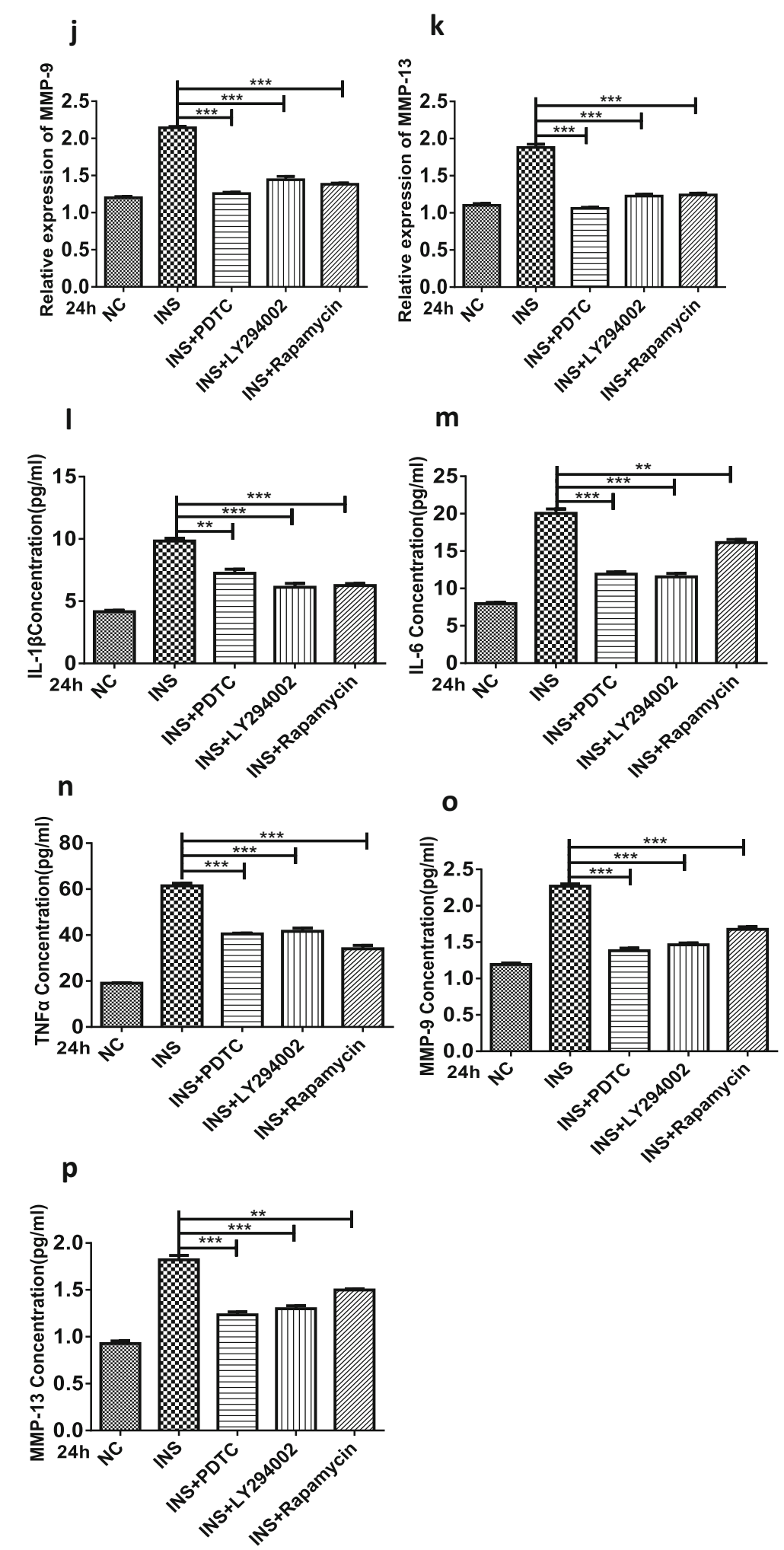

Fig. 4. (continued) 

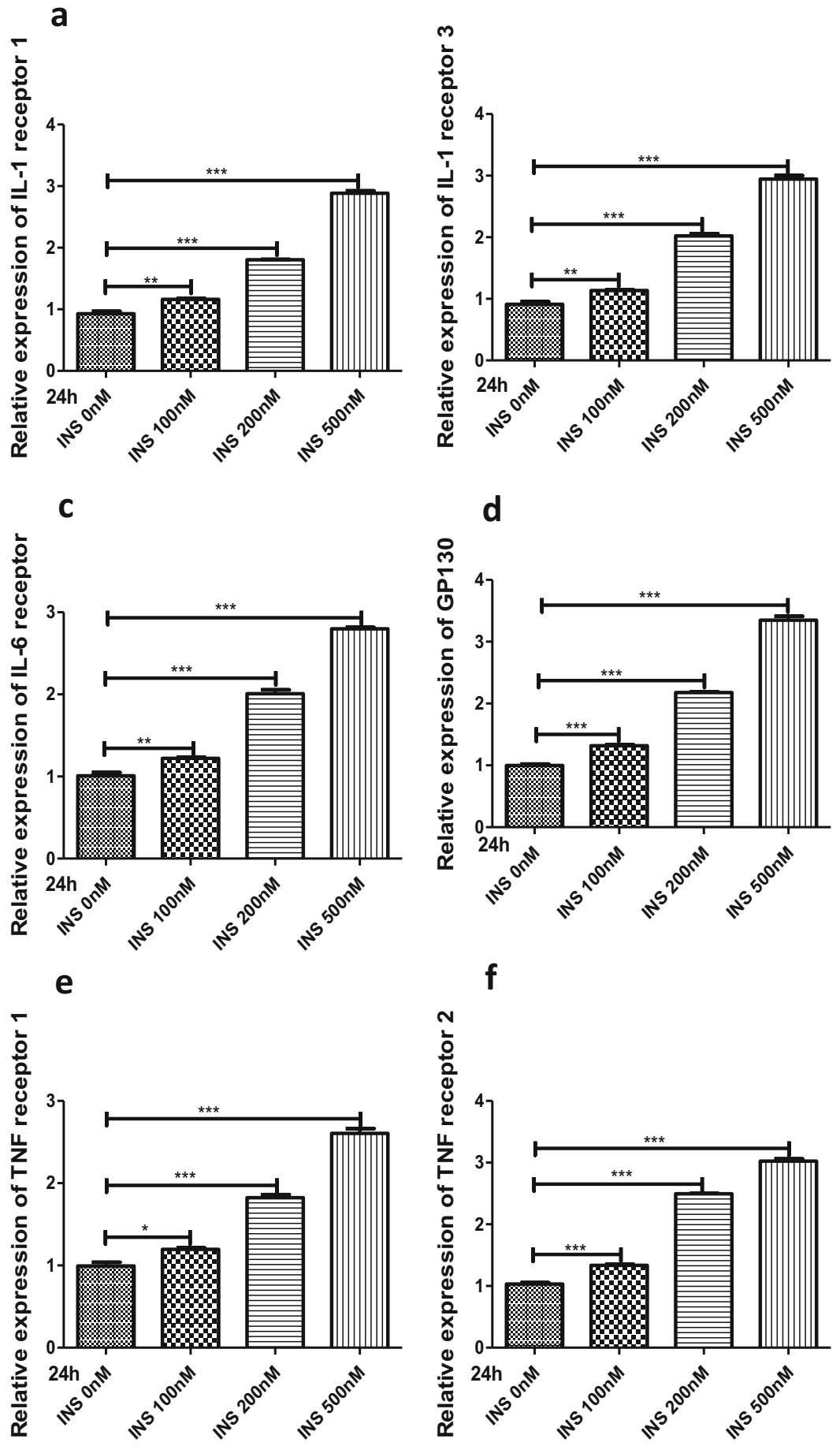

Fig. 5. Insulin upregulated surface receptors of inflammatory factors through PI $3 \mathrm{~K} / \mathrm{Akt} / \mathrm{mTOR}$ and NF-KB pathway in FLSs. a-f FLSs were treated with insulin $(0,100,200,500 \mathrm{nM})$ for 6,12 , or $24 \mathrm{~h}$. The expression and secretion of IL1R1, ILR3, IL6R, GP130, TNFR1, and TNFR2 were measured by qRTPCR. g-l Various inhibitors targeting NF-kB (PDTC, $10 \mu \mathrm{M}$ ), PI3K/Akt (LY294002, $10 \mu \mathrm{M}$ ), and mTOR (Rapamycin, $10 \mu \mathrm{M})$ were pre-treated for $6 \mathrm{~h}$ to antagonize the effects of insulin stimulation with a duration of $24 \mathrm{~h}$. To ascertain the expression and secretion of IL1R1, ILR3, IL6R, GP130, TNFR1, and TNFR2 in FLSs, qRT-PCR was performed. All the results are expressed as the mean \pm SEM of three experiments conducted in triplicate separately. $* P<0.05$. $* * P<0.01$. *** $P<0.001$ vs. control group. 

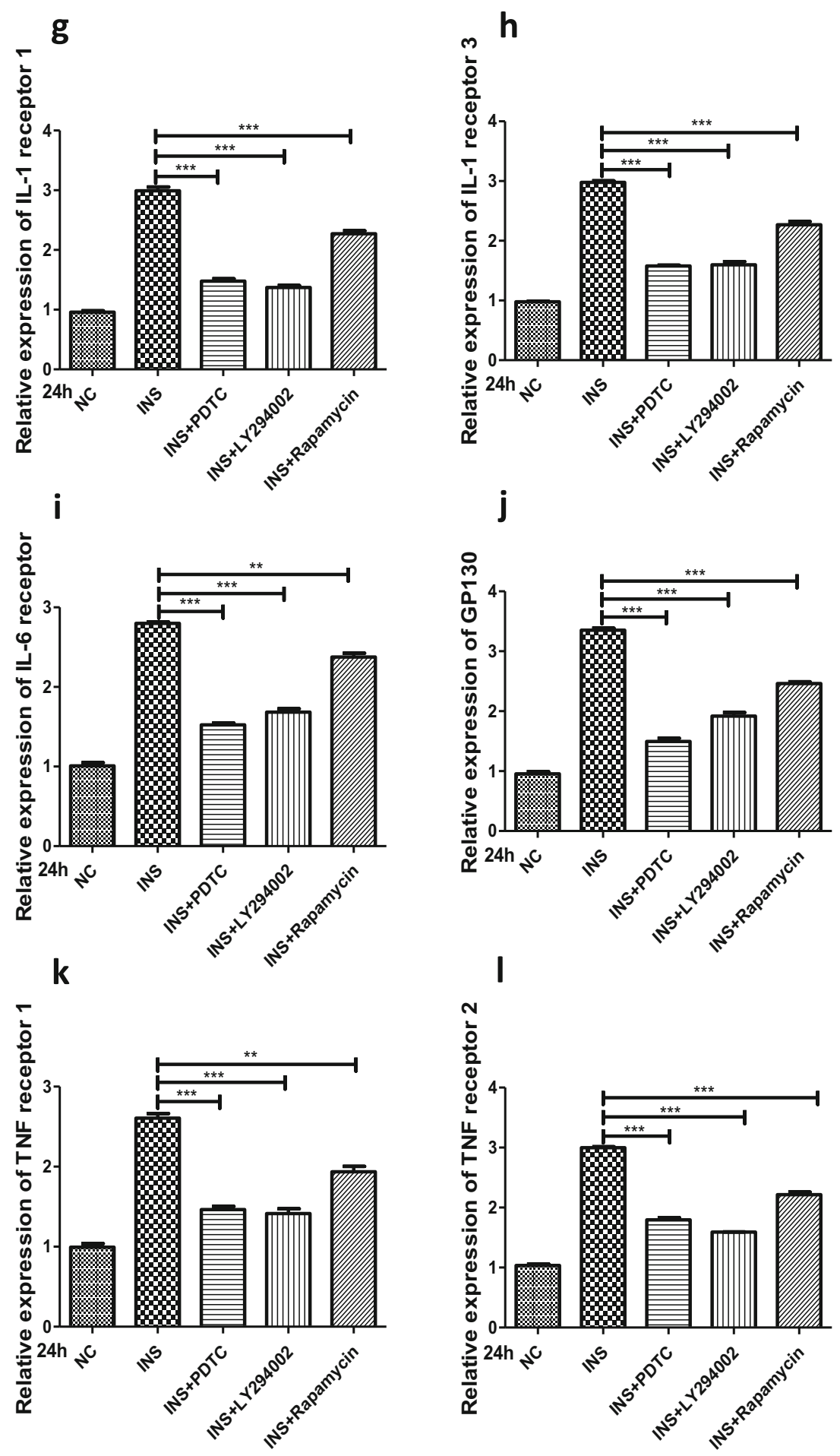

Fig. 5. (continued)

$50 \mathrm{ng} / \mathrm{ml})$ or were cotreated with high insulin $(500 \mathrm{nM})$ and all three cytokines separately for comparison. The qRT-
PCR results showed that the expression of MMP-9 and MMP-13 increased $(P<0.05)$ after treatment with IL- 

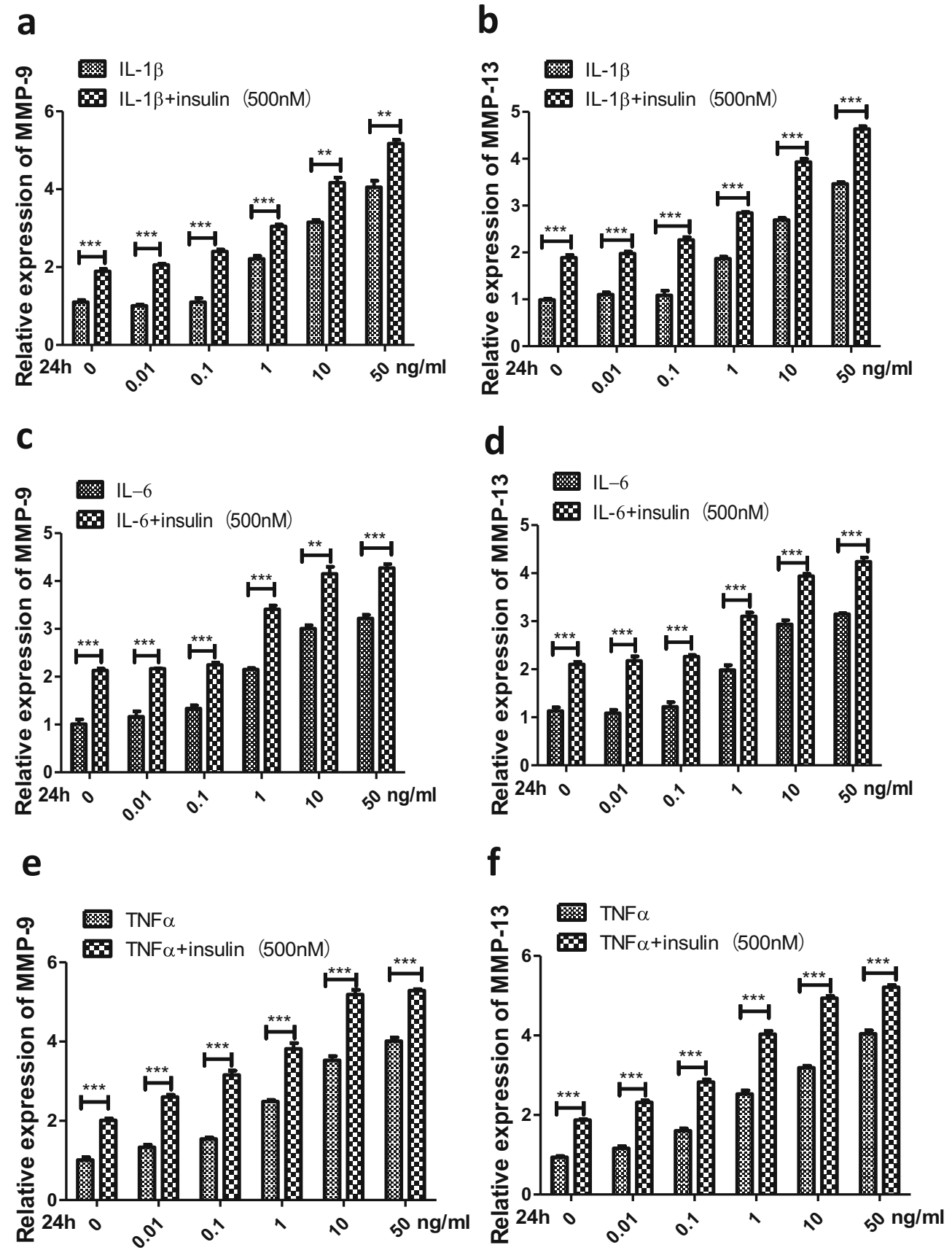

Fig. 6. Effects of insulin on expression of MMPs and regulation of signaling pathways by inflammatory cytokines. a-f FLSs were treated for $24 \mathrm{~h}$ with IL$1 \beta$, IL-6, and TNF- $\alpha(0,0.01,0.1,1,10,50 \mathrm{ng} / \mathrm{ml})$ separately, or insulin $(500 \mathrm{nM})$ was pre-treated for $12 \mathrm{~h}$ to affect the effects of inflammatory cytokines stimulation with a duration of $24 \mathrm{~h}$. The expression of MMP-9 and MMP-13 were measured by qRT-PCR. $\mathrm{g}$ FLSs were treated for $24 \mathrm{~h}$ with IL-1 $\beta$, IL-6, and TNF- $\alpha(50 \mathrm{ng} / \mathrm{ml})$ separately, or insulin (INS:500 nM) was pre-treated for $12 \mathrm{~h}$ to affect the effects of inflammatory cytokines stimulation with a duration of $24 \mathrm{~h}$. The phosphorylation level of PI3K/Akt/mTOR and p50/p65 were measured by Western blotting. All the results are expressed as the mean \pm SEM of three experiments conducted in triplicate separately. $* * P<0.01$. $* * * P<0.001 v s$. control group.

$1 \beta$, IL-6 and TNF- $\alpha(0,0.01,0.1,1,10$, or $50 \mathrm{ng} / \mathrm{ml})$ at $24 \mathrm{~h}$; the MMPs were increased most significantly
$(P<0.01)$ at the $50 \mathrm{ng} / \mathrm{ml}$ concentration, and the response was further increased by the presence of insulin (Fig. 6a-f). 


\section{g}

INS

$+$
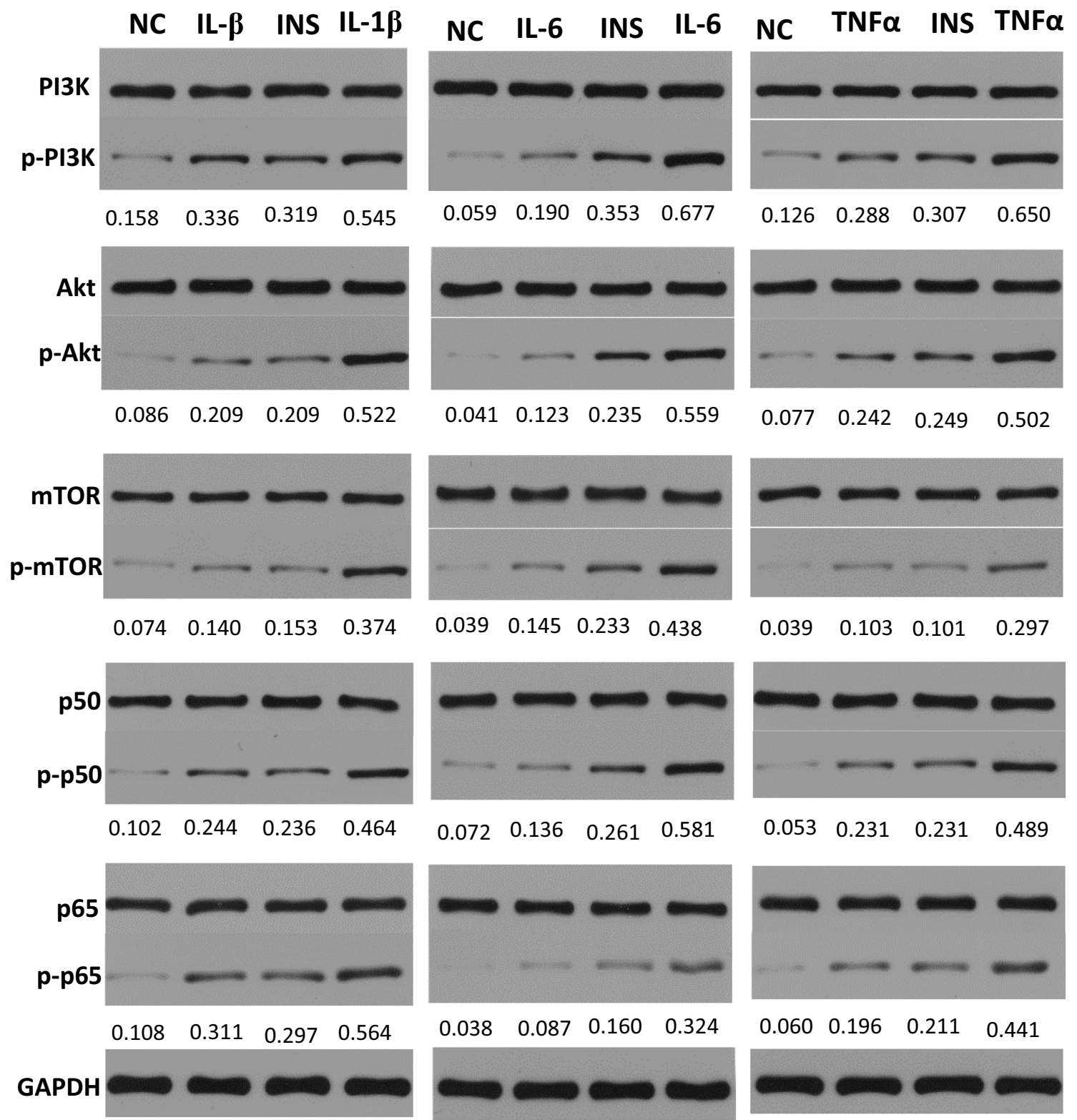

Fig. 6. (continued)

Finally, we sought to investigate whether insulin could affect IL-1 $\beta$, IL- 6 and TNF- $\alpha$-mediated signaling activation in FLSs, as suggested by the increase in cytokine-induced MMP expression. FLSs were treated with inflammatory cytokines (IL- $1 \beta$, IL- 6 and TNF- $\alpha$, $50 \mathrm{ng} / \mathrm{ml})$ and insulin $(500 \mathrm{nM})$ separately or cotreated with the two stimuli simultaneously. Western blotting was used to test the phosphorylation of PI3K/Akt/mTOR and p50/p65 in different groups. After treatment, the PI3K/Akt/ mTOR and p50/p65 phosphorylation levels in the three groups increased significantly and were even higher in the cotreatment group than in the other two groups (Fig. 6g). These experiments showed that insulin sensitized cellular signaling transduction activation by inflammatory 
cytokines. Based on the above-mentioned research, we suggest that insulin is involved in a positive feedback loop between IL-1 $\beta / \mathrm{IL}-6 / \mathrm{TNF}-\alpha$ and PI3K/mTOR/Akt/NF-kB signaling in FLSs.

\section{DISCUSSION}

In this study, we first discovered that insulin can promote synovial inflammation in the progression of osteoarthritis, either alone or in conjunction with inflammatory factors. First, insulin can significantly promote the inflammatory phenotype of FLSs, increase cell viability and inflammatory cytokine production, promote chemokine production, and enhance macrophage chemotaxis. Second, insulin can activate the PI3K/mTOR/Akt/NF-кB signaling pathway and simultaneously inhibit autophagy in FLSs. Third, our data suggest that the insulin-induced inflammatory responses are significantly reduced by preblocking three signaling pathways with specific pathway inhibitors in FLSs. Finally, the data show that insulin can upregulate inflammatory cytokine receptor levels in FLSs, and PI3K/mTOR/ $\mathrm{Akt} / \mathrm{NF}-\mathrm{kB}$ signaling inhibitors can reverse this process. More importantly, insulin has a sensitizing effect on inflammatory factor-mediated synovial inflammation (including MMP production and intracellular signaling pathway activation). Taken together, these data suggest that insulin may exacerbate synovial inflammatory lesions and thus contribute to the progression of OA.

Recent studies have demonstrated a close relationship between the pathogenesis of OA and metabolic syndrome based on insulin resistance and hyperinsulinemia $[15,16]$. Nicola et al. found a positive correlation between T2DM, characterized by hyperinsulinemia, and the development of OA [16]. Previous study suggested that insulin could promote the production of various proinflammatory factors (such as ILs, TNF- $\alpha$, MMP-13) associated with OA [1619]. In addition, insulin can inhibit chondrocyte maturation and promote cartilage degradation in vitro, thus aggravating the pathological changes of OA $[19,20]$. Synovial tissues, especially FLSs, have been shown to play a vital role in the development of OA [4-7]. However, until now, the effect of insulin on fibroblast synovial inflammation in OA was unclear. In this study, we found that insulin could exacerbate the inflammatory phenotype of OA FLSs. Thus, we hypothesized that insulin could promote OA progression through regulating the biological activity of various cell types.
Previous study showed that the PI3K/AKT and mTOR signaling pathways are implicated in the pathophysiological effects of insulin in OA [19, 40, 41]. NF$\mathrm{KB}$ determines the expression of inflammatory factors and MMPs in the joints and is considered to play a very important role in the pathogenesis of OA [2, 11-14]. This study found that insulin can aggravate the inflammatory phenotype of fibroblast synovial cells by activating the $\mathrm{PI} 3 \mathrm{~K} / \mathrm{mTOR} / \mathrm{Akt} / \mathrm{NF}-\mathrm{kB}$ signaling pathways. Our results confirm previous research that the $\mathrm{PI} 3 \mathrm{~K} / \mathrm{mTOR} / \mathrm{Akt} / \mathrm{NF}$ $\mathrm{KB}$ pathway was involved in the proinflammatory effects of insulin towards FLSs. The production of inflammatory factors and activation of signaling pathways in OA FLSs were enhanced with the stimulation of insulin in combination with other proinflammatory factors, such as IL- $1 \beta$, IL6 , and TNF- $\alpha$, further supporting these findings. These results indicate that insulin can do more than promote synovial inflammatory lesions alone; it can also work synergistically with inflammatory factors, participate in and activate the positive feedback loop between inflammatory factors and signal pathways, and further amplify the synovial inflammation cascade.

Autophagy is an important cellular process that maintains homeostasis and is involved in the pathogenesis of many inflammatory diseases. Notably, autophagy inhibition is closely related to the pathogenesis of OA [25]. Studies by Ribeiro et al. [19] have shown that insulin can lead to proteoglycan component loss and inflammatory cytokine and MMP increases in chondrocytes, and these effects may be achieved by inhibiting chondrocyte autophagy. In addition, the clinical data of this study showed that autophagy decreased in the knee cartilage of diabetic patients compared with non-diabetic patients; namely, the expression of the autophagy-related protein LC3II decreased significantly. Notably, this study revealed that rapamycin, as an autophagy activator (also an mTOR signaling pathway inhibitor), can prevent insulinmediated reductions in autophagy and cartilage degradation [19]. Our results showed that high insulin could also aggravate the inflammatory responses of FLSs by coordinating the autophagy process. These facts indicate that insulin was also related to autophagy in the pathogenesis of OA and provide a mechanistic basis for the role of insulin in OA.

Previous studies have suggested that the biological effects of insulin differs in a dose- and cell-specific manner [19, 20, 40-46]. In addition to the effects on FLSs shown in this study, chondrocytes were also found to be affected by insulin [19, 20, 40-43]. However, insulin has been reported to play either an inductive or 
inhibitory role in chondrocyte differentiation [20, 43] and consequently ameliorate or impair cartilage degeneration $[19,42]$ at different concentrations. Furthermore, at the molecular level, the influence in which insulin exerts differed greatly as its concentration is extremely high or low $[40,45,46]$. Rosa et al. [40] found that low and supraphysiological insulin levels exert different effects on aggrecan and proteoglycan synthesis in chondrocytes, which may be due to different receptors for insulin. Moreover, Mirdamadi [45] et al. found that high insulin $(1 \mu \mathrm{M})$ reduced the FoxO transcriptional activity, while low insulin $(0.1 \mu \mathrm{M})$ reduced the FoxO transcriptional activity of SZ95 sebocytes in vitro. Studies by Kubota et al. [46] showed that insulin selectively regulates specific downstream responses of the Akt pathway in a dose-dependent manner. Thus, we concluded that different mechanisms of insulin action were associated with different insulin concentrations, which may modulate the cellular response. Previous studies have shown that specific cellular responses could be achieved only after treatment with high concentrations of insulin [47-54]. Consistently, our data showed that insulin's effects on FLSs, which were exerted in a concentration-dependent manner, were more obvious as the concentration of insulin is super physiological. Taken together with these studies, it is obvious that different effector cells involved in the complex pathophysiologic process of various diseases have different sensitivities to insulin $[19,40,43,47-$ 52]. Our research object is FLSs involved in OA, and the different cell type selected is also the reason why the insulin concentration used in this study is different from that of other studies. As the insulin levels were significantly higher in the early stages of T2DM compared with those in non-diabetic individuals, our data may explain why patients with T2DM are more susceptible to OA than non-diabetic individuals. Therefore, although the insulin concentration chosen in our study is supraphysiological, our data still has reference value and clinical guiding significance.

In conclusion, our study demonstrated that insulin exacerbates the inflammatory phenotype involving $\mathrm{PI} 3 \mathrm{~K} / \mathrm{Akt} / \mathrm{mTOR} / \mathrm{NF}-\mathrm{KB}$ signaling of OA FLSs. Furthermore, autophagy was identified as another way for insulin to participate in the pathological progression of OA. Therefore, although the detailed regulatory mechanism needs to be further investigated, this study provides molecular evidence that insulin is closely related to OA by regulating the biological activity of FLSs, and blocking insulin-mediated pathway holds potential as a novel treatment strategy.

\section{AUTHORS' CONTRIBUTIONS}

The study was designed, and funding was provided by SS and YL; the study was conducted, and the manuscript was prepared by LQ and SS; most experiments were performed by LQ; the data were studied by LQ and SS; samples were provided by LQ and SS. The final manuscript was read and approved by all authors.

\section{FUNDING INFORMATION}

This study was financed by the Natural Science Foundation of Shandong (NO.ZR2018MH007) and National Natural Science Foundation of China (NO.81972056).

COMPLIANCE WITH ETHICAL STANDARDS

Ethics Approval and Consent to Participate. This study was permitted by the Ethics Committee of Shandong Provincial Hospital Affiliated to Shandong University (Jinan, China) on March 3, 2017 (approval number 2017-53).

Conflict of Interest. The authors declare that they have no conflict of interest.

Open Access This article is licensed under a Creative Commons Attribution 4.0 International License, which permits use, sharing, adaptation, distribution and reproduction in any medium or format, as long as you give appropriate credit to the original author(s) and the source, provide a link to the Creative Commons licence, and indicate if changes were made. The images or other third party material in this article are included in the article's Creative Commons licence, unless indicated otherwise in a credit line to the material. If material is not included in the article's Creative Commons licence and your intended use is not permitted by statutory regulation or exceeds the permitted use, you will need to obtain permission directly from the copyright holder. To view a copy of this licence, visit http://creativecommons.org/licenses/by/4.0/.

\section{REFERENCES}

1. Global Burden of Disease Study 2013 Collaborators. 2015. Global, regional, and national incidence, prevalence, and years lived with disability for 301 acute and chronic diseases and injuries in 188 countries, 1990-2013: a systematic analysis for the Global Burden Disease Study 2013. Lancet. 386 (9995): 743-800. https://doi.org/ 10.1016/S0140-6736(15)60692-4. 
2. Kapoor, M., J. Martel-Pelletier, D. Lajeunesse, J.P. Pelletier, and H. Fahmi. 2011. Role of proinflamatory cytokines in the pathophysiology of osteoarthritis. Nature Reviews Rheumatology 7 (1): 33-42. https://doi.org/10.1038/nrrheum.2010.196.

3. Wang, T., and C. He. 2018. Pro-inflammatory cytokines: the link between obesity and osteoarthritis. Cytokine \& Growth Factor Reviews 44: 38-50. https://doi.org/10.1016/j.cytogfr.2018.10.002.

4. Moradi, B., N. Rosshirt, E. Tripel, J. Kirsch, A. Barié, F. Zeifang, T. Gotterbarm, and S. Hagmann. 2015. Unicompartmental and bicompartmental knee osteoarthritis show different patterns of mononuclear cell infiltration and cytokine release in the affected joints. Clinical and Experimental Immunology 180 (1): 143-154. https:// doi.org/10.1111/cei.12486.

5. Klein-Wieringa, I.R., B.J. de Lange-Brokaar, E. Yusuf, S.N. Andersen, J.C. Kwekkeboom, H.M. Kroon, G.J. van Osch, A.M. Zuurmond, V. Stojanovic-Susulic, R.G. Nelissen, R.E. Toes, M. Kloppenburg, and A. Ioan-Facsinay. 2016. Inflammatory cells in patients with endstage knee osteoarthritis: a comparison between the synovium and the infrapatellar fat pad. Journal of Rheumatology 43 (4): 771-778. https://doi.org/10.3899/jrheum.151068.

6. Wang, X., D.J. Hunter, X. Jin, and C. Ding. 2018. The importance of synovial inflammation in osteoarthritis: current evidence from imaging assessments and clinical trial. Osteoarthritis Cart 26 (2): 165167. https://doi.org/10.1016/j.joca.2017.11.015.

7. Bhattaram, P., and U. Chandrasekharan. 2017. The joint synovium: a critical determinant of articular cartilage fate in inflammatory joint diseases. Seminars in Cell \& Developmental Biology 62: 86-93. https://doi.org/10.1016/j.semcdb.2016.05.009.

8. Scanzello, C.R., and S.R. Goldring. 2012. The role of synovitis in osteoarthritis pathogenesis. Bone 51 (2): 249-257. https://doi.org/ 10.1016/j.bone.2012.02.012.

9. Pozgan, U., D. Caglic, B. Rozman, H. Nagase, V. Turk, and B. Turk. 2010. Expression and activity profiling of selected cysteine cathepsins and matrix metalloproteinases in synovial fluids from patients with rheumatoid arthritis and osteoarthritis. Biological Chemistry 391 (5): 571-579. https://doi.org/10.1515/BC.2010.035.

10. Larsson, S., M. Englund, A. Struglics, and L.S. Lohmander. 2015. Interleukin-6 and tumor necrosis factor alpha in synovial fluid are associated with progression of radiographic knee osteoarthritis in subjects with previous meniscectomy. Osteoarthritis and Cartilage 23 (11): 1906-1914. https://doi.org/10.1016/j.joca.2015.05.035.

11. Rigoglou, S., and A.G. Papavassiliou. 2013. The NF-kappaB signalling pathway in osteoarthritis. International Journal of Biochemistry \& Cell Biology 45 (11): 2580-2584. https://doi.org/10.1016/ j.biocel.2013.08.018.

12. Zheng, W., Z. Feng, Y. Lou, C. Chen, and C. Zhang. 2017. Silibinin protects against osteoarthritis through inhibiting the inflammatory response and cartilage matrix degradation in vitro and in vivo. Oncotarget 8 (59): 99649-99665. https://doi.org/10.18632/ oncotarget.20587.

13. Tokito, A., and M. Jougasaki. 2016. Matrix metalloproteinases in non-neoplastic disorders. International Journal of Molecular Sciences 17 (7): 1178. https://doi.org/10.3390/ijms17071178.

14. Malemud, C.J. 2017. Matrix metalloproteinases and synovial joint pathology. Progress in Molecular Biology and Translational Science 148: 305-325. https://doi.org/10.1016/bs.pmbts.2017.03.00.

15. Courties, A., J. Sellam, and F. Berenbaum. 2017. Metabolic syndrome-associated osteoarthritis. Current Opinion in Rheumatology 29 (2): 214-222. https://doi.org/10.1097/ BOR.000000000000037310.1038/nrrheum.2017.50.

16. Veronese, N., C. Cooper, J.Y. Reginster, M. Hochberg, J. Branco, O. Bruere, R. Chapurlat, N. Al-Daghri, E. Dennison, G. Herrero-Beaumont, J.F. Kaux, E. Maheu, R. Rizzoli, R. Roth, L.C. Rovati, D.
Uebelhart, M. Vlaskovska, and A. Scheen. 2019. Type 2 diabetes mellitus and osteoarthritis. Seminars in Arthritis and Rheumatism 49 (1): 9-19. https://doi.org/10.1016/j.semarthrit.2019.01.005.

17. Lubberts, E. 2015. The IL-23-IL-17 axis in inflammatory arthritis. Nature Reviews Rheumatology 11 (7): 415-429. https://doi.org/ 10.1038/nrrheum.2015.53.

18. Berenbaum, F. 2011. Diabetes-induced osteoarthritis: from a new paradigm to a new phenotype. Annals of the Rheumatic Diseases 70 (8): 1354-1356. https://doi.org/10.1136/ard.2010.146399.

19. Ribeiro, M., P. Lo'pez de Figueroa, F.J. Blanco, A.F. Mendes, and B. Carame's. 2016. Insulin decreases autophagy and leads to cartilage degradation. Osteoarthritis and Cartilage 24 (4): 731-739. https:// doi.org/10.1016/j.joca.2015.10.017.

20. Torres, E., C. Andrade, E. Fonseca, M. Mello, and M. Duarte M. 2003. Insulin impairs the maturation of chondrocytes in vitro. Brazilian Journal of Medical and Biological Research 36 (9): 11851192. https://doi.org/10.1590/s0100-879x2003000900007.

21. Feng, Y., D. He, Z. Yao, and D.J. Klionsky. 2014. The machinery of macroautophagy. Cell Research 24 (1): 24-41. https://doi.org/ 10.1038/cr.2013.168.

22. Mizushima, N., and M. Komatsu. 2011. Autophagy: renovation of cells and tissues. Cell 147 (4): 728-741. https://doi.org/10.1016/ j.cell.2011.10.026.

23. Li, Y.S., F.J. Zhang, C. Zeng, W. Luo, W.F. Xiao, S.G. Gao, and G.H. Lei. 2016. Authophagy in osteoarthritis. Joint, Bone, Spine 83 (2): 143-148. https://doi.org/10.1016/j.jbspin.2015.06.009.

24. Cheng, N.T., H. Meng, L.F. Ma, L. Zhang, H.M. Yu, Z.Z. Wang, and A. Guo. 2017. Role of autophagy in the progression of osteoarthritis: the autophagy inhibitor, 3-methyladenine, aggravates the severity of experimental osteoarthritis. International Journal of Molecular Medicine 39 (5): 1224-1232. https://doi.org/10.3892/ ijmm.2017.2934.

25. Caramés, B., M. Olmer, W.B. Kiosses, and M.K. Lotz. 2015. The relationship of autophagy defects to cartilage damage during joint aging in a mouse model. Arthritis \& Rheumatology 67 (6): 15681576. https://doi.org/10.1002/art.39073.

26. Mizushima, N., T. Yoshimori, and B. Levine. 2010. Methods in mammalian autophagy research. Cell 140 (3): 313-326. https:// doi.org/10.1016/j.cell.2010.01.028.

27. Caramés, B., A. Hasegawa, N. Taniguchi, S. Miyaki, F.J. Blanco, and M. Lotz. 2012. Autophagy activation by rapamycin reduces severity of experimental osteoarthritis. Annals of the Rheumatic Diseases 71 (4): 575-581. https://doi.org/10.1136/annrheumdis2011-200557.

28. He, W., and Y. Cheng. 2018. Inhibition of miR-20 promotes proliferation and autophagy in articular chondrocytes by PI3K/AKT/ mTOR signaling pathway. Biomedicine \& Pharmacotherapy 97: 607-615. https://doi.org/10.1016/j.biopha.2017.10.152.

29. Xue, J.F., Z.M. Shi, J. Zou, and X.L. Li. 2017. Inhibition of $\mathrm{PI} 3 \mathrm{~K} / \mathrm{AKT} / \mathrm{mTOR}$ signaling pathway promotes autophagy of articular chondrocytes and attenuates inflammatory response in rats with osteoarthritis. Biomedicine \& Pharmacotherapy 89: 1252-1261. https://doi.org/10.1016/j.biopha.2017.01.130.

30. Wullschleger, S., R. Loewith, and M.N. Hall. 2006. TOR signaling in growth and metabolism. Cell 124 (3): 471-484. https://doi.org/ 10.1016/j.cell.2006.01.016.

31. Engelman, J.A. 2009. Targeting PI3K signaling in cancer: opportunities, challenges and limitations. Nature Reviews Cancer 9 (8): 550-562. https://doi.org/10.1038/nrc2664.

32. Sallusto, F., and M. Baggiolini. 2008. Chemokines and leukocyte traffic. Nature Immunology 9 (9): 949-952. https://doi.org/10.1038/ ni.f.214. 
33. Bachelerie, F., A. Ben-Baruch, A.M. Burkhardt, C. Combadiere, J.M. Faeber, G.J. Graham, R. Horuk, A.H. Sparre-Ulrich, M. Locati, A.D. Luster, A. Mantovani, K. Matsushima, P.M. Murphy, R. Nibbs, H. Nomiyama, C.A. Power, A.E. Proudfoot, M.M. Rosenkilde, A. Rot, S. Sozzani, M. Thelen, O. Yoshie, and A. Zlotnik. 2014. International union of basic and clinical pharmacology. LXXXIX. Update on the extended family of chemokine receptors and introducing a new nomenclature for atypical chemokine receptors. Pharmacological Reviews 66 (1): 1-79. https://doi.org/10.1124/ pr.113.007724.

34. Sánchez-Martín, L., A. Estecha, R. Samaniego, S. Sánchez-Ramón, M.Á. Vega, and P. Sánchez-Mateos. 2011. The chemokine CXCL12 regulates monocyte-macrophage differentiation and RUNX3 expression. Blood 117 (1): 88-97. https://doi.org/10.1182/blood2009-12-258186.

35. Svensson, S., A. Abrahamsson, G.V. Rodriguez, A.K. Olsson, L. Jensen, Y. Cao, and C. Dabrosin. 2015. CCL2 and CCL5 are novel therapeutic targets for estrogen-dependent breast cancer. Clinical Cancer Research 21 (16): 3794-3805. https://doi.org/10.1158/ 1078-0432.CCR-15-0204.

36. Scanzello, C.R. 2017. Chemokines and inflammation in osteoarthritis: Insights from patients and animal models. Journal of Orthopaedic Research 35 (4): 735-739. https://doi.org/10.1002/jor.23471.

37. Boraschi, D., P. Italiani, S. Weil, and M.U. Martin. 2018. The family of the interleukin-1 receptors. Immunological Reviews 281 (1): 197232. https://doi.org/10.1111/imr.12606.

38. Baran, P., S. Hansen, G.H. Waetzig, M. Akbarzadeh, L. Lamertz, H.J. Huber, M.R. Ahmadian, J.M. Moll, and J. Scheller. 2018. The balance of interleukin (IL)-6, IL-6-soluble IL-6 receptor (sIL-6R), and IL-6·sIL-6R·sgp130 complexes allows simultaneous classic and trans-signaling. Journal of Biological Chemistry 293 (18): 67626775. https://doi.org/10.1074/jbc.RA117.001163.

39. Becker, D., T. Deller, and A. Vlachos. 2015. Tumor necrosis factor (TNF)-receptor 1 and 2 mediate homeostatic synaptic plasticity of denervated mouse dentate granule cells. Scientific Reports 5: 12726. https://doi.org/10.1038/srep12726.

40. Rosa, S.C., A.T. Rufino, F. Judas, C. Tenreiro, M.C. Lopes, and A.F. Mendes. 2011. Expression and function of the insulin receptor in normal and osteoarthritic human chondrocytes: modulation of anabolic gene expression, glucose transport and GLUT-1 content by insulin. Osteoarthritis and Cartilage 19 (6): 719-727. https:// doi.org/10.1016/j.joca.

41. Claassen, H., M. Schlüter, M. Schünke, and B. Kurz. 2006. Influence of 17beta-estradiol and insulin on type II collagen and protein synthesis of articular chondrocytes. Bone 39 (2): 310-317. https:// doi.org/10.1016/j.bone.2006.02.067.

42. Cai, L., F.W. Okumu, J.L. Cleland, M. Beresini, D. Hogue, Z. Lin, and E.H. Filvaroff. 2002. A slow release formulation of insulin as a treatment for osteoarthritis. Osteoarthritis and Cartilage 10 (9): 692-706. https://doi.org/10.1053/joca.2002.0813.

43. Phornphutkul, C., K.Y. Wu, and P.A. Gruppuso. 2006. The role of insulin in chondrogenesis. Molecular and Cellular Endocrinology 249 (1-2): 107-115. https://doi.org/10.1016/j.mce.2006.02.002.

44. Rossetto, R., M.V.A. Saraiva, M.P. Bernuci, G.M. Silva, I.R. Brito, A.M.C.V. Alves, D.M. Magalhães-Padilha, S.N. Báo, C.C.
Campello, A.P.R. Rodrigues, and J.R. Figueiredo. 2016. Impact of insulin concentration and mode of FSH addition on the in vitro survival and development of isolated bovine preantral follicles. Theriogenology 86 (4): 1137-1145. https://doi.org/10.1016/ j.theriogenology.2016.04.003.

45. Kubota, H., R. Noguchi, Y. Toyoshima, Y. Ozaki, S. Uda, K. Watanabe, W. Ogawa, and S. Kuroda. 2012. Temporal coding of insulin action through multiplexing of the AKT pathway. Molecular Cell 46 (6): 820-832. https://doi.org/10.1016/j.molce.

46. Mirdamadi, Y., A. Thielitz, A. Wiede, A. Goihl, E. Papakonstantinou, R. Hartig, C.C. Zouboulis, D. Reinhold, L. Simeoni, U. Bommhardt, S. Quist, and H. Gollnick. 2015. Insulin and insulin-like growth factor-1 can modulate the phosphoinositide-3-kinase/Akt/FoxO1 pathway in SZ95 sebocytes in vitro. Molecular and Cellular Endocrinology 415: 32-44. https://doi.org/10.1016/j.mce.2015.08.001.

47. Ho-Palma, A.C., P. Toro, F. Rotondo, M.D.M. Romero, M. Alemany, X. Remesar, and J.A. Fernández-López. 2019. Insulin controls triacylglycerol synthesis through control of glycerol metabolism and despite increased lipogenesis. Nutrients 11 (3): 513. https:// doi.org/10.3390/nu11030513.

48. de Proença, A.R.G., K.D. Pereira, L. Meneguello, L. Tamborlin, and A.D. Luchessi. 2019. Insulin action on protein synthesis and its association with eIF5A expression and hypusination. Molecular Biology Reports 46 (1): 587-596. https://doi.org/10.1007/s11033018-4512-1.

49. Hodonu, A., M. Escobar, L. Beach, J. Hunt, and J. Rose. 2019. Glycogen metabolism in mink uterine epithelial cells and its regulation by estradiol, progesterone and insulin. Theriogenology 130: 6270. https://doi.org/10.1016/j.theriogenology.2019.02.023.

50. Chen, C.D., S. Podvin, E. Gillespie, S.E. Leeman, and C.R. Abraham. 2007. Insulin stimulates the cleavage and release of the extracellular domain of Klotho by ADAM10 and ADAM17. Proceedings of the National Academy of Sciences of the United States of America 104 (50): 19796-19801. https://doi.org/10.1073/pnas.0709805104.

51. Montagnani, M., L.V. Ravichandran, H. Chen, D.L. Esposito, and M.J. Quon. 2002. Insulin receptor substrate-1 and phosphoinositidedependent kinase-1 are required for insulin-stimulated production of nitric oxide in endothelial cells. Molecular Endocrinology 16 (8): 1931-1942. https://doi.org/10.1210/me.2002-0074.

52. Zeng, G., F.H. Nystrom, L.V. Ravichandran, L.N. Cong, M. Kriby, H. Mostowski, and M.J. Quon. 2000. Roles for insulin receptor, PI3kinase, and Akt in insulin-signaling pathways related to production of nitric oxide in human vascular endothelial cells. Circulation 101 (13): 1539-1545. https://doi.org/10.1161/01.cir.101.13.1539.

53. Wu, K., W. Wang, H. Chen, W. Gao, and C. Yu. 2019. Insulin promotes proliferation of pancreatic ductal epithelial cells by increasing expression of PLK1 through PI3K/AKT and NF-kB pathway. Biochemical and Biophysical Research Communications 509 (4): 925-930. https://doi.org/10.1016/j.bbrc.

54. Desbois-Mouthon, C., A. Cadoret, M.J. Blivet-Van Eggelpoël, F. Bertrand, G. Cherqui, C. Perret, and J. Capeau. 2001. Insulin and IGF-1 stimulate the beta-catenin pathway through two signalling cascades involving GSK-3beta inhibition and Ras activation. Oncogene 20 (2): 252-259. https://doi.org/10.1038/sj.onc.1204064.

\section{PUBLISHER'S NOTE}

Springer Nature remains neutral with regard to jurisdictional claims in published maps and institutional affiliations. 